\title{
Membrane transporters and protein traffic networks differentially affecting metal tolerance: a genomic phenotyping study in yeast Roberta Ruotolo, Gessica Marchini and Simone Ottonello
}

\author{
Address: Department of Biochemistry and Molecular Biology, Viale G.P. Usberti 23/A, University of Parma, I-4310o Parma, Italy. \\ Correspondence: Simone Ottonello. Email: s.ottonello@unipr.it
}

Published: 7 April 2008

Received: 29 December 2007

Genome Biology 2008, 9:R67 (doi:10.1 186/gb-2008-9-4-r67)

Revised: 26 February 2008

The electronic version of this article is the complete one and can be Accepted: 7 April 2008

found online at http://genomebiology.com/2008/9/4/R67

(c) 2008 Ruotolo et al.; licensee BioMed Central Ltd.

This is an open access article distributed under the terms of the Creative Commons Attribution License (http://creativecommons.org/licenses/by/2.0), which permits unrestricted use, distribution, and reproduction in any medium, provided the original work is properly cited.

\begin{abstract}
Background: The cellular mechanisms that underlie metal toxicity and detoxification are rather variegated and incompletely understood. Genomic phenotyping was used to assess the roles played by all nonessential Saccharomyces cerevisiae proteins in modulating cell viability after exposure to cadmium, nickel, and other metals.

Results: A number of novel genes and pathways that affect multimetal as well as metal-specific tolerance were discovered. Although the vacuole emerged as a major hot spot for metal detoxification, we also identified a number of pathways that play a more general, less direct role in promoting cell survival under stress conditions (for example, mRNA decay, nucleocytoplasmic transport, and iron acquisition) as well as proteins that are more proximally related to metal damage prevention or repair. Most prominent among the latter are various nutrient transporters previously not associated with metal toxicity. A strikingly differential effect was observed for a large set of deletions, the majority of which centered on the ESCRT (endosomal sorting complexes required for transport) and retromer complexes, which - by affecting transporter downregulation and intracellular protein traffic - cause cadmium sensitivity but nickel resistance.

Conclusion: The data show that a previously underestimated variety of pathways are involved in cadmium and nickel tolerance in eukaryotic cells. As revealed by comparison with five additional metals, there is a good correlation between the chemical properties and the cellular toxicity signatures of various metals. However, many conserved pathways centered on membrane transporters and protein traffic affect cell viability with a surprisingly high degree of metal specificity.
\end{abstract}

\section{Background}

Metals, especially the nonessential ones, are a major environmental and human health hazard. The molecular bases of their toxicity as well as the mechanisms that cells have evolved to cope with them are rather variegated and incompletely understood. The soft acid cadmium and the borderline acid nickel are nonessential transition metals of great environmental concern. Although redox inactive, cadmium and nickel cause oxidative damage indirectly [1] and they both have carcinogenic effects $[2,3]$, albeit with reportedly different mechanisms [1,4-6]. 
The cellular effects of cadmium are far more studied than those of nickel. Instrumental to the elucidation of some of the basic mechanisms that underlie cadmium toxicity has been the model eukaryote Saccharomyces cerevisiae [7]. It was studies conducted in this organism, for example, that yielded the first demonstration of the indirect nature of cadmium's genotoxic effects, which leads to genome instability by inhibiting DNA mismatch repair [8] and other DNA repair systems [6]. Similarly, lipid peroxidation as a major mechanism of cadmium toxicity [9] as well as the central roles played by thioredoxin and reduced glutathione (GSH) [7], and vacuolar transport systems such as Ycf1 [10], in cadmium detoxification were first documented in yeast. Some of the above components were shown to be upregulated at both the mRNA $[11,12]$ and protein $[12,13]$ levels in cadmium-stressed yeast cells. Predominant among these expression changes was the upregulation of the sulfur amino acid biosynthetic pathway and the induction of isozymes with a markedly reduced sulfur amino acid content as a way to spare sulfur for GSH synthesis [12]. A number of additional cadmium-responsive genes without any obvious relationship to sulfur sparing or cadmium stress were also identified, however. Curiously, only a small subset of the most cadmium-responsive genes produce a metal-sensitive phenotype when deleted [13], thus reinforcing the notion that transcriptional modulation per se is not a general predictor of the pathways influencing stress tolerance $[14,15]$. For example, deletion of genes coding for two major organic peroxide-scavenging enzymes (GPX3 and AHP1; the latter encoding a cadmium-induced alkyl hydroperoxide reductase) did not impair cadmium tolerance [13].

By comparison, only a few studies have dealt with nickel toxicity in yeast. Interestingly, they showed that unprogrammed gene silencing, which is a major mechanism of nickel toxicity and carcinogenicity in humans [16,17], also operates in S. cerevisiae. This further emphasizes the high degree of conservation of various aspects of metal toxicity as well as the usefulness of $S$. cerevisiae as a model organism for elucidating the corresponding pathways in humans. They also suggest, however, that a broad and as yet largely unexplored range of cellular pathways may be involved in alleviating the toxic effects of metals. What is currently missing, in particular, is a global view of such pathways at the phenotype level and a genome-wide comparison of different metals as well as other stressors.

We have addressed these issues by examining the fitness of a genome-wide collection of yeast deletion mutant strains $[18,19]$ exposed to two chemically diverse metals, namely cadmium and nickel, each of which is a known carcinogen $[2,3,20]$. This allowed us to assess the role of all nonessential proteins in modulating the cellular toxicity (sensitivity or resistance) of these two metals. The results of this screen were integrated with interactome data and compared with the genomic phenotyping profiles of other stressors. To gain further insight into the cytotoxicity signatures of different met- als, the entire set of 388 mutants exhibiting an altered viability after exposure to cadmium and nickel was challenged with four additional metals (mercury, zinc, cobalt and iron) plus the metalloid $\mathrm{AsO}_{2}{ }^{-}$. Although overall there is good correlation between the chemical properties and the cellular toxicity signatures of various metals, many conserved pathways centered on (but not limited to) membrane transporters and protein traffic affect cell viability with a surprisingly high degree of metal specificity.

\section{Results and discussion}

Genomic phenotyping of cadmium and nickel toxicity

Sublethal concentrations of $50 \mu \mathrm{mol} / \mathrm{l}$ cadmium and 2.5 $\mathrm{mmol} / \mathrm{l}$ nickel (see 'Materials and methods', below, for details) were used for multireplicate screening of the yeast haploid deletion mutant collection (five replicates for each metal), which was performed by manually pinning ordered sets of 384 strains onto metal-containing yeast extract-peptone-dextrose (YPD)-agar plates (Additional data file 1 [Figure $\mathrm{S} 1 \mathrm{~A}]$ ). After culture and colony size inspection, strains scored as metal sensitive or resistant in at least three screens were individually verified by spotting serial dilutions onto metal-containing plates. Mutant strains exhibiting various levels of metal sensitivity (high sensitivity [HS], medium sensitivity [MS], and low sensitivity [LS]) and a single class of metal resistant mutant strains were recognized (Additional data file 1 [Figures $\mathrm{S} 1 \mathrm{~B}$ and $\mathrm{S} 1 \mathrm{C}]$ ).

A total of 388 mutant strains that were sensitive or resistant to cadmium and/or nickel were identified. As shown in Figure 1a, some of them were specifically sensitive or resistant to cadmium or nickel, whereas others exhibited an altered tolerance to both metals. Metal-sensitive mutants exceeded the resistant ones by more than threefold. The number of sensitive mutants was considerably higher for cadmium than for nickel, which is in accordance with the strikingly different cellular toxicity previously reported for these two metal ions in animal cells $[4,21]$. Conversely, mutants resistant to nickel were significantly more abundant than cadmium-resistant mutant strains. More than two-thirds of the nickel-resistant mutants were found to be sensitive to cadmium, as opposed to only one instance of cadmium resistance/nickel sensitivity $\left(s m f_{1} \Delta\right)$. A detailed list of the mutants, including their degree of sensitivity (Additional data file 1 [Figures S1B and $\mathrm{S} 1 \mathrm{C}$ ]), Gene Ontology (GO) description, and related information, is provided in Additional data file 2. Human orthologs were identified for about $50 \%$ of the genes causing metal sensitivity or resistance, 27 of which correspond to genes previously found to be involved in human diseases, especially cancer. Twenty-four mutants are deleted in genes encoding uncharacterized open reading frames (ORFs), whereas four metal toxicity modulating genes are homologous to unannotated human ORFs (Additional data file 2). Genomic phenotyping data were also compared with the results of transcriptomic 


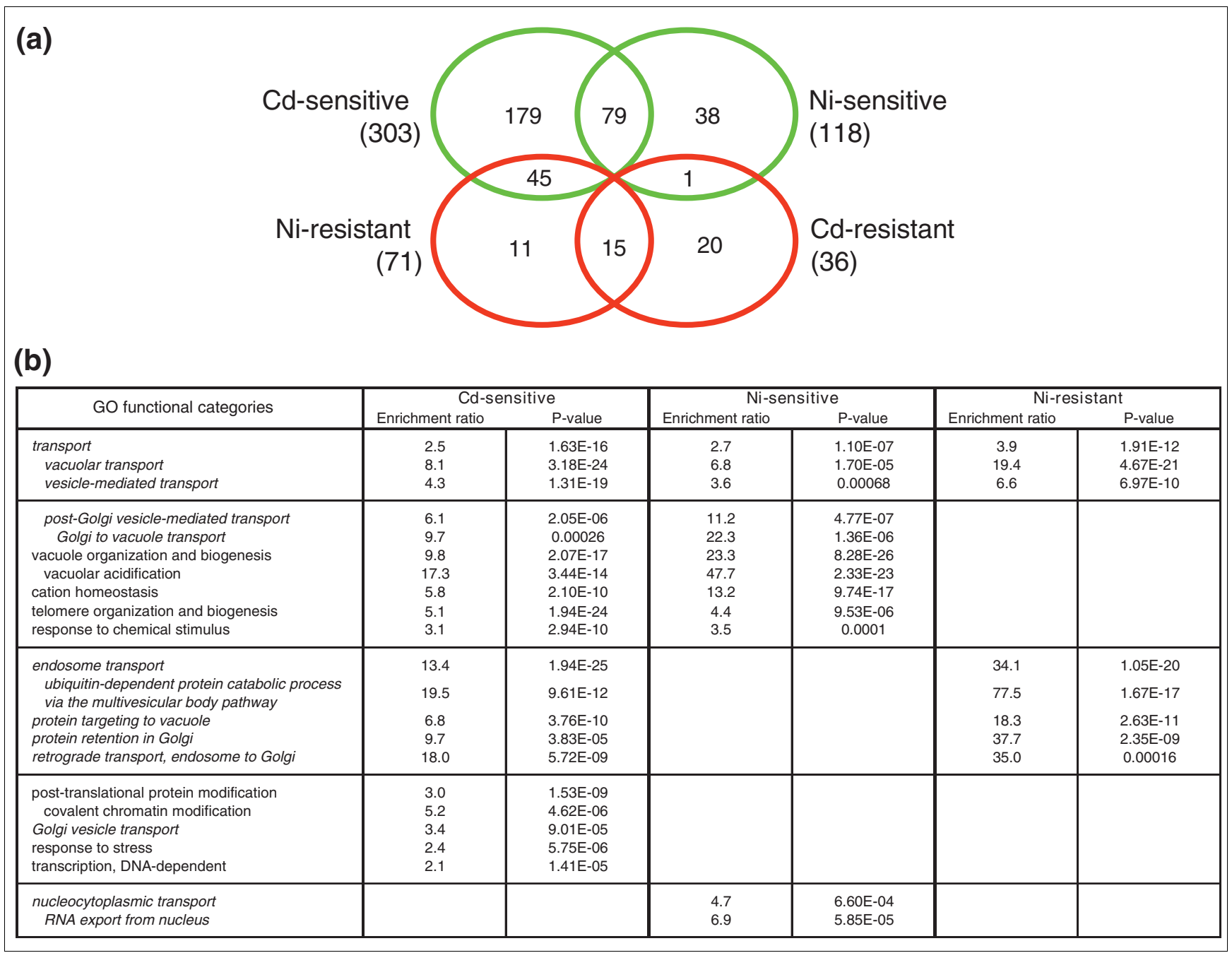

\section{Figure I}

Distribution among different sensitivity/resistance groups and functional classification of metal tolerance affecting mutations. (a) Venn diagram visualization of mutant strains displaying multimetal or metal-specific sensitivity (green circles) or resistance (red circles); also shown are mutants characterized by an opposite phenotypic response to the two metals (45 cadmium sensitive/nickel resistant strains and one cadmium resistant/nickel sensitive strain). (b) Biologic processes associated with metal toxicity-modulating genes identified with the Gene Ontology (GO) Term Finder program [99]. Statistical significance of GO term/gene group association $(P$-value $<0.00 \mathrm{I})$ and enrichment ratios are reported for each category; parent terms are presented in bold, and child terms of the parent class 'transport' are presented in italics.

analyses conducted on cadmium-treated yeast cells [11]. In keeping with previous comparisons of this kind $[14,15]$, only a marginal (about 7\%) overlap was detected (Additional data file 2).

As revealed by the GO analysis summarized in Figure $1 \mathrm{~b}$, a wide range of cellular processes is engaged in the modulation of cadmium and nickel toxicity. At variance with cadmium resistant mutants, which are scattered throughout various GO categories, nickel-resistant as well as cadmium/nickelsensitive mutant strains were found to be enriched in specific functional categories. Some of the top responsive genes identified by previous expression profiling studies (for example, genes involved in GSH and reduced sulfur metabolism $[11,13])$ were found to be among deletion mutants specifically sensitive to cadmium, especially within the 'response to stress' category. As expected for cells treated with agents that are actively internalized by and sequestered into vacuoles, a number of the most significant GO categories are related to 'transport', particularly to the vacuole, and to the biogenesis and functioning (for example, acidification) of this organelle. Several processes not so obviously associated with metal tolerance were also identified. For example, 'nucleocytoplasmic transport' (including nuclear pore complex formation, and functionality) emerged as a process that is specifically impaired in nickel-sensitive mutants. Other processes centered on vesicle-mediated transport also profoundly influence cadmium and nickel tolerance in different, often contrasting ways. For example, many 'Golgi-to-vacuole transport' mutants appear to be sensitive to both cadmium and 
nickel, whereas defects in 'endosome transport' and 'retrograde transport endosome-to-Golgi' render cells sensitive to cadmium but resistant to nickel (see below).

Importantly, mutants with metal sensitivity phenotypes of varying severity (Additional data files 1 and 2) are present within different mutant classes as well as functional categories. This discounts the possibility that only highly sensitive mutant strains or particular classes of genes are relevant to cadmium/nickel tolerance, and suggests that a suite of pathways, much broader than previously thought, modulates metal tolerance in eukaryotic cells.

\section{Mutations impairing cadmium and nickel tolerance}

To gain a more detailed understanding of metal toxicity-modulating pathways and the way in which they are interconnected, we set out to analyze genome phenotyping data in the framework of the known yeast interactome [22-24]. The 79 genes that when mutated cause sensitivity to both cadmium and nickel were initially addressed. As shown in Figure 2, 52 of these genes were identified as part of nine functional subnetworks (a minimum of three gene products sharing at least one GO biological process annotation and connected by at least two physical or genetic interactions; see 'Materials and methods', below, for details on this analysis). Seventeen of the remaining genes could be traced to a particular subnetwork but did not pass the above criterion, whereas the other ten remained as 'solitary' entries. Metal sensitivity phenotypes for at least two deletion mutants randomly sampled from each subnetwork were confirmed by independent serial dilution assays carried out on untagged strains of the opposite mating type (data not shown).

In accordance with the tight relationship between metal tolerance and vacuole functionality highlighted by GO analysis, the most populated subnetwork (subnetwork 1 ; $P$-value $<1.5$ $\times 10^{-18}$ ) comprises a large set of subunits, assembly factors, and regulators of V-ATPase, which is the enzyme responsible for generating the electrochemical potential that drives the

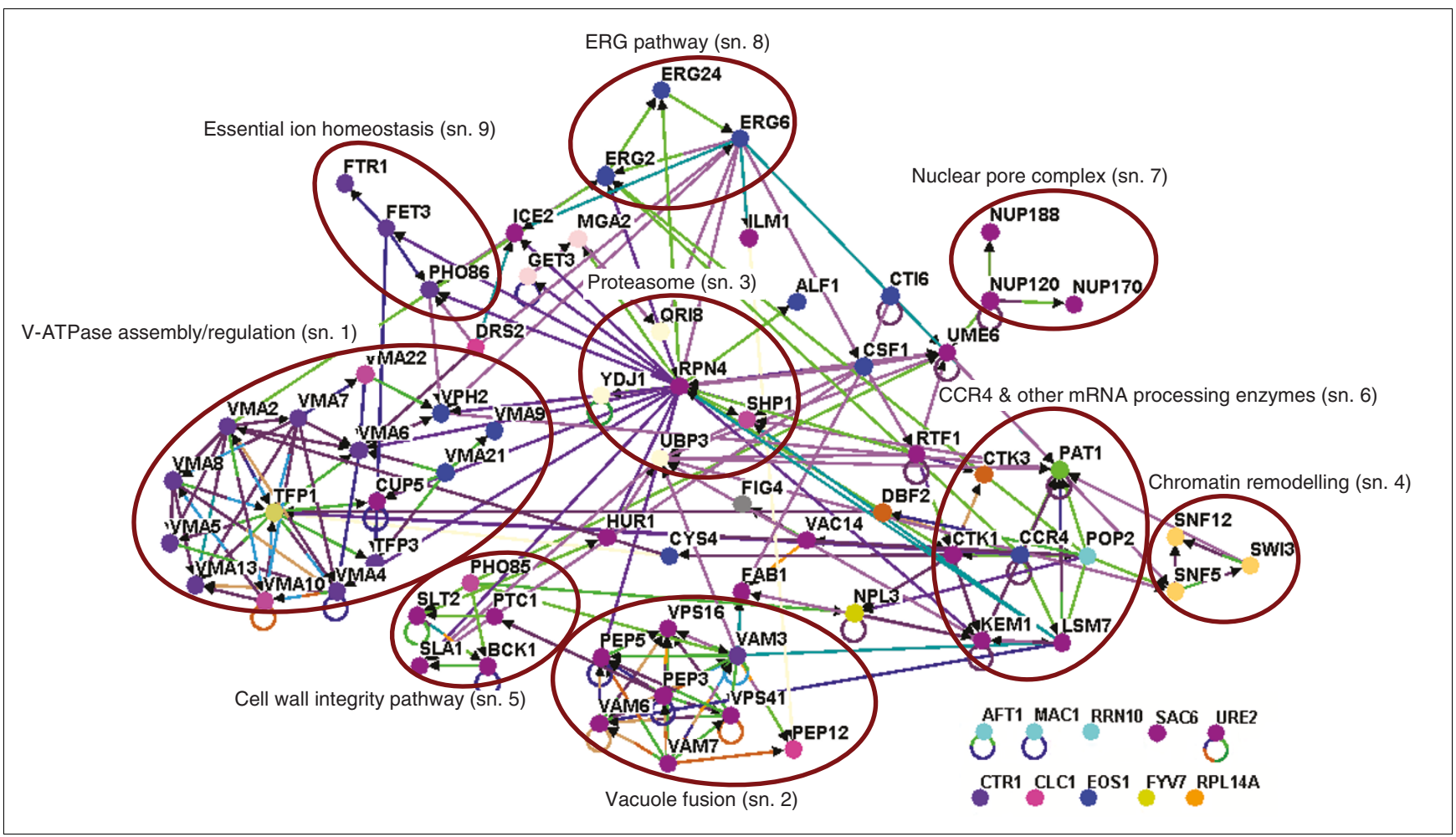

Figure 2

Interaction subnetworks among gene products whose disruption causes cadmium/nickel sensitivity. Physical (I I0) and genetic (I05) interactions were identified computationally using the Network Visualization System Osprey [103]. Gene products are represented as nodes, shown as filled circles colored according to their Gene Ontology (GO) classification; interactions are represented as node-connecting edges, shown as lines, colored according to the type of experimental approach utilized to document interaction as specified in the BioGRID database [22] and in the Osprey reference manual. The nine identified subnetworks (a minimum of three interacting gene products sharing at least one GO biologic process annotation and connected by at least two physical or genetic interactions; see 'Materials and methods') are encircled and associated with a general function descriptor. Thirteen interacting gene products whose interaction or functional similarity features do not satisfy the above criterion are shown outside encircled subnetworks; genes without any reported interaction (or linked via essential genes, not addressed in this study) are shown at the bottom. Individual subnetworks were subjected to independent verification by serial dilution growth assays carried on at least two untagged strains of the opposite mating type (see 'Materials and methods'). sn., subnetwork. 
active accumulation of various ions within the vacuole [25]. Also related to V-ATPase functionality (although not included in subnetwork 1) is Cys4, which is the first enzyme of cysteine biosynthesis, whose disruption indirectly interferes with vacuolar $\mathrm{H}^{+}$-ATPase activity [26]. Another highly populated subnetwork (subnetwork 2; $P$-value $<2 \times 10^{-5}$ ) contains eight additional vacuole-related genes belonging to either class $\mathrm{B}$ or $\mathrm{C}$ 'vacuolar protein sorting' (vps) mutants, whose deletion respectively causes a fragmented vacuole morphology or lack of any vacuole-like structure [27,28]. This indicates that defects in specific aspects of vacuole functionality as well as in late steps of vesicle transport to, and fusion with, the vacuole cause sensitivity to both metal ions. In keeping with this view, three additional proteins (Fab1, Fig4, and Vac14), which also cause cadmium/nickel sensitivity when disrupted, control trafficking to the vacuolar lumen [29,30]. The role played by the vacuole in metal toxicity modulation may entail both metal sequestration within this organelle as well as the clearance of metal-damaged macromolecules.

Connected with these vacuole-related hot spots, which include a number of genes previously associated with cadmium (but not nickel) tolerance [7], are five additional subnetworks. One of them (subnetwork 3; $P$-value $<7 \times 10^{-2}$ ) comprises the master regulator Rpn4, which is required for proteasome biogenesis, and three ubiquitin-related proteasomal components (Qri8, Shp1, and Ubp3), thus reinforcing the notion that abnormal protein degradation plays an important role in toxic metal tolerance [31-33]. Other components previously associated with tolerance to cadmium and to other stressors include three subunits of the chromatin remodeling complex SWI/SNF (SWItch/Sucrose NonFermenting; subnetwork 4; $P$-value < 0.1) [34] and a group of regulators of the cell wall integrity/mitogen-activated protein kinase signaling pathway (subnetwork $5 ; P$-value $<3.4 \times 10^{-6}$ ) [35,36]. These are functionally linked to the second largest subnetwork (subnetwork 6; $P$-value $<9.1 \times 10^{-5}$ ), which is centered on Ccr4 and its associated proteins. Ccr 4 is a multifunctional mRNA deadenylase that can be part of mRNA decay as well as transcriptional regulatory complexes in association with the NOT factors [37]. None of the NOT deletion mutants was identified as metal sensitive, whereas a few other transcriptional regulators interacting with Ccr4 (for example, Dbf2 and Rtf1) cause cadmium/nickel sensitivity when disrupted. Pop2, another major deadenylase in $S$. cerevisiae [37], along with three additional RNA processing enzymes (Kem1, Lsm7, and Pat1), were also found among cadmium/nickel sensitive mutants. Previously known to be involved in the response to DNA damaging agents [38], these proteins thus appear to play a role also in metal tolerance, which might be aimed at ensuring proper translational/metabolic reprogramming under stress conditions. This finding, along with the identification of cadmium/nickel-sensitive mutations affecting three nuclear pore complex subunits (subnetwork $7 ; P$-value $<7.3$ $\left.\times 10^{-4}\right)$ and a mRNA export factor (Npl3), points to mRNA decay and trafficking (particularly nuclear export) as a novel hot spot of metal toxicity.

The last two subnetworks pertain to ergosterol biosynthesis (subnetwork 8; $P$-value $<9.8 \times 10^{-4}$ ), which critically influences the structural and functional integrity of the plasma membrane (Additional data file 1 [Figure S1B] shows a representative phenotype), and to essential ion homeostasis (subnetwork 9; $P$-value $<$ o.12). The latter includes the endoplasmic reticulum exit protein Pho86, which is required for plasma membrane translocation of the Pho84 phosphate transporter, the high-affinity iron transport complex Ftr1/ Fet3, and a transcription factor (encoded by the solitary gene $A F T 1$ ) that positively regulates $F T R 1 / F E T 3$ expression. All these genes cause cadmium/nickel sensitivity when mutated. A possible explanation for this finding is that toxic metals can make iron, and other essential ions, limiting for cell growth (see below). In fact, one copper transporter (Ctr1) and a copper uptake-related transcription factor (Mac1) were also found among the cadmium/nickel-sensitive mutants in our screen.

\section{Metal-specific sensitive mutants}

A similar interactome analysis was applied to deletion mutants that proved to be specifically sensitive to nickel or cadmium. As shown in Table 1 (and Additional data files 3 and 4), this led to the identification of seven metal-specific subnetworks and to the inclusion of nickel and cadmium specific mutants into previously identified subnetworks. Especially noteworthy are the nickel-specific expansion of the nuclear pore complex (subnetwork $7 ; P$-value $<1 \times 10^{-4}$ ) and the many cadmium-specific mutants added to subnetwork 4 ( $P$-value $<1.7 \times 10^{-3}$ ), which includes various components of the chromatin modification complexes SAGA and INO80, plus the histone deacetylase HDA1. Proteins involved in histone acetylation may affect metal tolerance by influencing DNA reactivity as well as DNA accessibility to repair enzymes, or by influencing the expression of genes needed for recovery. The selective enrichment of cadmium-sensitive mutants within this subnetwork (as well as in the cadmium-specific subnetwork 'DNA repair'; subnetwork 12; see below) is not too surprising, if one considers the known genotoxic effects of cadmium, caused by interference with DNA repair $[6,8]$.

Only one of the new subnetworks (subnetwork 10; $P$-value < $1.6 \times 10^{-3}$ ) was found to be specifically associated with nickel sensitivity (Table 1 and Additional data file 3 ). This includes various components of a multiprotein complex (Adaptor Protein complex AP-3) that is involved in the alkaline phosphatase (ALP) pathway for protein transport from the Golgi to the vacuole. At variance with the other Golgi-to-vacuole transport route (the so-called 'carboxypeptidase Y' [CPY] pathway), which proceeds through an endosome intermediate and includes a number of components that when disrupted cause cadmium sensitivity (see subnetwork 15 in Table 1), the ALP pathway directly targets its cargo proteins to the 
Table I

Subnetwork organization of gene products whose disruption specifically affects nickel or cadmium tolerance

\begin{tabular}{|c|c|c|c|c|}
\hline \multirow[t]{2}{*}{ Subnetworks ${ }^{a}$} & \multicolumn{2}{|c|}{ Nickel } & \multicolumn{2}{|c|}{ Cadmium } \\
\hline & Interacting gene products & $\begin{array}{l}\text { Functionally linked } \\
\text { gene products }\end{array}$ & Interacting gene products ${ }^{3}$ & $\begin{array}{l}\text { Functionally linked gene } \\
\text { products }, c\end{array}$ \\
\hline $\begin{array}{l}\text { V-ATPase assembly/regulation } \\
\text { (sn. I) }\end{array}$ & Ravl, Vmal6, VphI & & & \\
\hline Proteasome (sn. 3) & Cuel & & $\begin{array}{l}\text { Bre5, Cdc26, Doa I, Hlj।, Sell, } \\
\text { Ubi4, Ubp6, Umpl }\end{array}$ & Dia2 \\
\hline $\begin{array}{l}\text { Chromatin assembly/ } \\
\text { remodelling (sn. 4) }\end{array}$ & & & $\begin{array}{l}\text { SAGA complex (Ada2, ChdI, } \\
\text { Gcn5, Hfil, Nggl, Spt7*, Spt20); } \\
\text { Ino80 complex (Arp5, Arp8, } \\
\text { Tafl4); COMPASS complex } \\
\text { (Bre2, Sdcl); Asfl, ArdI, Eaf7*, } \\
\text { Esc2, Hdal*, Hmol, loc2 }\end{array}$ & Hmol \\
\hline $\begin{array}{l}\text { Cell wall integrity pathway (sn. } \\
\text { 5) }\end{array}$ & & Whi3 & $\begin{array}{l}\text { Bem2, Dom34, Ecm33, Kcs I, } \\
\text { Pin4, Pogl, Rvs 16I, Rvs I67, Sic I, } \\
\text { Sit4*, Sur7, Swi4, Swi6, Whi2 }\end{array}$ & \\
\hline $\begin{array}{l}\text { CCR4 and other mRNA } \\
\text { processing enzymes (sn. 6) }\end{array}$ & & & Dhhl & Pafl \\
\hline Nuclear pore complex (sn. 7) & Nup84, Sac3, Thpl & & & \\
\hline Essential ion homeostasis (sn. 9) & Pho88 & Ccc2, Zapl & Smf3 & Gefl, Pho89 \\
\hline AP-3 complex (sn. 10) & Apl5, Apl6, Apm3, Aps3 & & & \\
\hline General transcription (sn. II) & Mftl, Rpb9, Rtt 103, Thp2 & & $\begin{array}{l}\text { Mediator complexes (Gall I, } \\
\text { Med2, Pgd I, Spt2I, Srb8*, Srb I0); } \\
\text { CadI, Elp4, Tup I, YapI }\end{array}$ & MssII \\
\hline DNA repair (sn. 12) & & & $\begin{array}{l}\text { Ctf4, Himl, Met18, Mms22, } \\
\text { Mrel I, Pol32, Rad6, Rad27, Xrs2 }\end{array}$ & \\
\hline Antioxidant defense (sn. 13) & & & Atx2, CcsI, SodI, Sod 2 & $\begin{array}{l}\text { Cadl, Glrl, GshI, Gsh2, } \\
\text { Yapl, Zwfl }\end{array}$ \\
\hline Hog I pathway (sn. 14) & & & Fps I, Hogl, Pbs2, Rck2, Stel I & Gre2 \\
\hline $\begin{array}{l}\text { Vesicle targeting to, from or } \\
\text { within Golgi (sn. I5) }\end{array}$ & & & $\begin{array}{l}\text { Erv4I, Erv46, Get2, Sacl, Sec22, } \\
\text { Sec66; Vps 13; Cog5, Cog8; Pep7, } \\
\text { Tlg2, Vps3, Vps9, Vps2I, Vps45; } \\
\text { ArII, Arl3, Ent3, Gga2, Nhx I*, } \\
\text { RgpI, Ricl, Sys I, Yil039w*, } \\
\text { Vps5I, Vps54, Ypt6; Vam I0*, } \\
\text { VpsI*, Vps8*; Pep8*, Vps5*, } \\
\text { VpsI7*, Vps29*, Vps30*, Vps35*, } \\
\text { Vps38* }\end{array}$ & Apm2, Snx3* \\
\hline $\begin{array}{l}\text { Ubiquitin-dependent sorting to } \\
\text { the multivesicular body pathway } \\
\text { (sn. 16) }\end{array}$ & & & $\begin{array}{l}\text { Vps27*; ESCRT I complex } \\
\text { (Vps28*, Mvb I2*, Srn2*, Stp22*); } \\
\text { ESCRT II complex (Snf8*, Vps25*, } \\
\text { Vps36*); ESCRT-III complex } \\
\text { (Did4*, Snf**, Vps20*, Vps24*); } \\
\text { Brol*, Did2*, Doa4*, Vps4* }\end{array}$ & $\begin{array}{l}\text { Bsd2*, Bull*, Nhxl*, } \\
\text { Trel* }\end{array}$ \\
\hline
\end{tabular}

aSubnetworks I to 9 are the same as those described in Figure 2 but include deletion mutants specifically sensitive to nickel or cadmium (no nickel or cadmium specific mutants were identified for subnetworks 2 and 8); subnetworks 10 to 16 are newly identified interaction networks comprised of gene products causing nickel-specific or cadmium-specific sensitivity when disrupted (also see Additional data files 3 and 4 ). bGene products for which no physical or genetic interaction is documented in the BioGRID database [22] but for which a functional relationship with the indicated subnetworks has been reported. 'Gene mutations causing cadmium sensitivity but nickel resistance are marked with an asterisk. AP-3, Adaptor Protein-3; CCR, Carbon Catabolite Repression; ESCRT, endosomal sorting complexes required for transport; sn., subnetwork.

vacuole. Different metals and/or different metal-specific detoxifying proteins thus appear to be differentially trafficked through the Golgi-vacuole network. A similar differential toxicity effect was recently reported for iron and copper [39]. Also notable in this regard is the observation that mutants impaired in the retrieval of receptors from the endosome to the Golgi (subnetwork 15; $P$-value $<2.4 \times 10^{-3}$ ) and in endo- some-to-vacuole transport (subnetwork 16; $P$-value $<1.6 \times$ $10^{-8}$ ) are specifically sensitive to cadmium but resistant to nickel (see below).

The other cadmium-specific subnetworks are 'DNA repair' (subnetwork 12; $P$-value $<0.16$ ), which includes the ubiquitin-conjugating DNA repair enzyme RAD6; 'antioxidant 
defence' (subnetwork 13; $P$-value $<5.8 \times 10^{-2}$ ) and other functionally related components (Table 1 and Additional data file 4); and the Hog1 kinase cascade (subnetwork 14; $P$-value < $3.7 \times 10^{-2}$ ), which was previously shown to be involved in cadmium tolerance [40]. The latter, along with the upstreamacting kinase Pbs2, controls a number of cell wall integrityrelated genes. Other genes that when mutated cause cadmium or nickel sensitivity encode plasma membrane (Mal31 and Smf1) and intracellular (Ccc2, Pho88, Pho89, Smf3, Ybt1, and Ycf1) transporters (or transport-related proteins), for most of which involvement in toxic metal mobilization (especially export or reduced uptake) has not previously been reported (see below).

A previously underestimated variety of cellular processes, operating in different subcellular compartments (vacuole, Golgi, and endosome, but also cytosol, nucleus, and plasma membrane), thus appears to be involved in metal tolerance in yeast. Perhaps the most significant among the novel metal toxicity-related processes revealed by our screen are mRNA decay and nucleocytoplasmic transport, and the different protein trafficking (particularly vacuole-to-Golgi) pathways that differentially affect cadmium and/or nickel tolerance when disrupted.

\section{Cadmium and nickel interfere with iron homeostasis through different mechanisms}

To highlight potential commonalities between cadmium/ nickel exposure and other stresses, we compared our data with those obtained from similar genomic phenotyping studies [41-45]. As shown in Figure 3a, alkaline $\mathrm{pH}$ exhibited the closest overlap with cadmium/nickel stress. About $50 \%$ of the cadmium/nickel co-sensitive mutants (plus additional metalspecific mutants) correspond to genes previously shown to cause alkaline $\mathrm{pH}$ sensitivity when disrupted [44]. Furthermore, the toxicity phenotypes of both metals (particularly nickel) were exacerbated by increasing growth medium $\mathrm{pH}$ (Figure 3b). Especially notable among these shared (toxic metal/alkaline $\mathrm{pH}$ sensitive) mutants are those deleted in components directly or indirectly involved in iron homeostasis (for example, Aft1, Ctr1, Fet3/Ftr1, and Mac1), disruption of which leads to iron deficiency [46]. The latter has been implicated as a major determinant of alkaline $\mathrm{pH}$ stress through a reduction of iron solubility/availability [44] as well as a contributing factor to the stress induced by zinc overload in yeast, which has been shown to be caused by competition between zinc and iron at the level of cellular uptake [47]. Moreover, exposure to cadmium and nickel reduces intracellular iron levels in plant and animal cells [48-51]. We thus addressed the relationship between iron deficiency and cadmium/nickel toxicity by testing the effect of increasing iron concentrations on the fitness of cells lacking either subunit of Fet3/Ftr1 (deletion of which causes a genetic surrogate of iron starvation) exposed to either cadmium or nickel.
As shown in Figure 4, supplementation of $30 \mu \mathrm{mol} / \mathrm{l} \mathrm{FeCl}_{3}$ increased cadmium/nickel tolerance in fet3 $\Delta$ cells (same results for the ftr1 $\Delta$ mutant; data not shown). An ameliorating effect of iron supplementation was observed with other mutants not so closely related to iron homeostasis (for example, erg2 $\Delta$, slt2 $\Delta$, vam7 4 , and vps51 4 ; data not shown), suggesting that iron deficiency is indeed an important (albeit indirect) determinant of cadmium/nickel toxicity. However, it should be noted that - at variance with cadmium, whose toxicity was progressively alleviated by increasing iron concentrations even in wild-type (WT) cells - nickel toxicity was only partly relieved in the fet3 $\Delta$ mutant within a narrow, 30 to $60 \mu \mathrm{mol} / \mathrm{l} \mathrm{FeCl}_{3}$ supplementation range, and gradually deteriorated thereafter (Figure 4).

Also apparent in Figure 4 is the different degree of cadmium/ nickel sensitivity of the fet3 $\Delta$ mutant (same for ftr1 $\Delta$ ), which is only moderately sensitive to cadmium (LS phenotype) but highly sensitive to nickel (HS phenotype). Other distinguishing features of the iron-related phenotypes of cadmium and nickel originate from the low-affinity/low-specificity transporters encoded by the $F E T 4$ and $S M F 1$ genes $[46,52]$. These transporters become major entry sites for iron under iron overload or fet3/ftr1 $\Delta$ conditions [53,54] as well in the absence of the transcription factor Aft1, which positively regulates FET3 and FTR1, whose deletion causes a HS phenotype for both cadmium and nickel (Additional data file 1 [Figure $\mathrm{S} 1 \mathrm{~B}]$ shows a representative phenotype). In addition to iron, Fet4 and Smf1 internalize other metals such as manganese, copper and cadmium $[52,55,56]$, whereas no conclusive data on nickel have thus far been reported. In keeping with this notion, we find that fet 4 and $s m f_{1}$ deletion mutants are cadmium (but not nickel) resistant, whereas disruption of Rox1 a negative regulator of $\mathrm{FET}_{4}$ - makes cells selectively sensitive to cadmium (Additional data file 5). Conversely, over-expression of Smf1 causes cadmium (but not nickel) sensitivity (see Figures 7 and 8, below, for representative phenotypes). Therefore, even though cadmium and nickel toxicity is exacerbated at alkaline $\mathrm{pH}$ and both interfere with iron homeostasis, they probably do so with different mechanisms.

Cadmium, but not nickel, is internalized by broad-range transporters such as Fet4, which accumulate under iron-limiting conditions as a way to cope with iron deficiency [54]. Two nonmutually exclusive mechanisms may thus explain the alleviating effect of iron supplementation on cadmium toxicity, in both WT and fet3 $\Delta$ cells: competition between the two metals at the level of cellular uptake; and downregulation of promiscuous (iron/cadmium) transporters under conditions of iron overload [54,57]. Competitition between iron and cadmium at the level of cellular uptake may account, for instance, for the anti-cadmium effect of iron that has been described in rats fed with a iron-supplemented diet [58]. Nickel, instead, interferes with iron homeostasis via an as yet unidentified mechanism, which does not appear to rely on direct competition with iron at the level of cellular uptake. An 


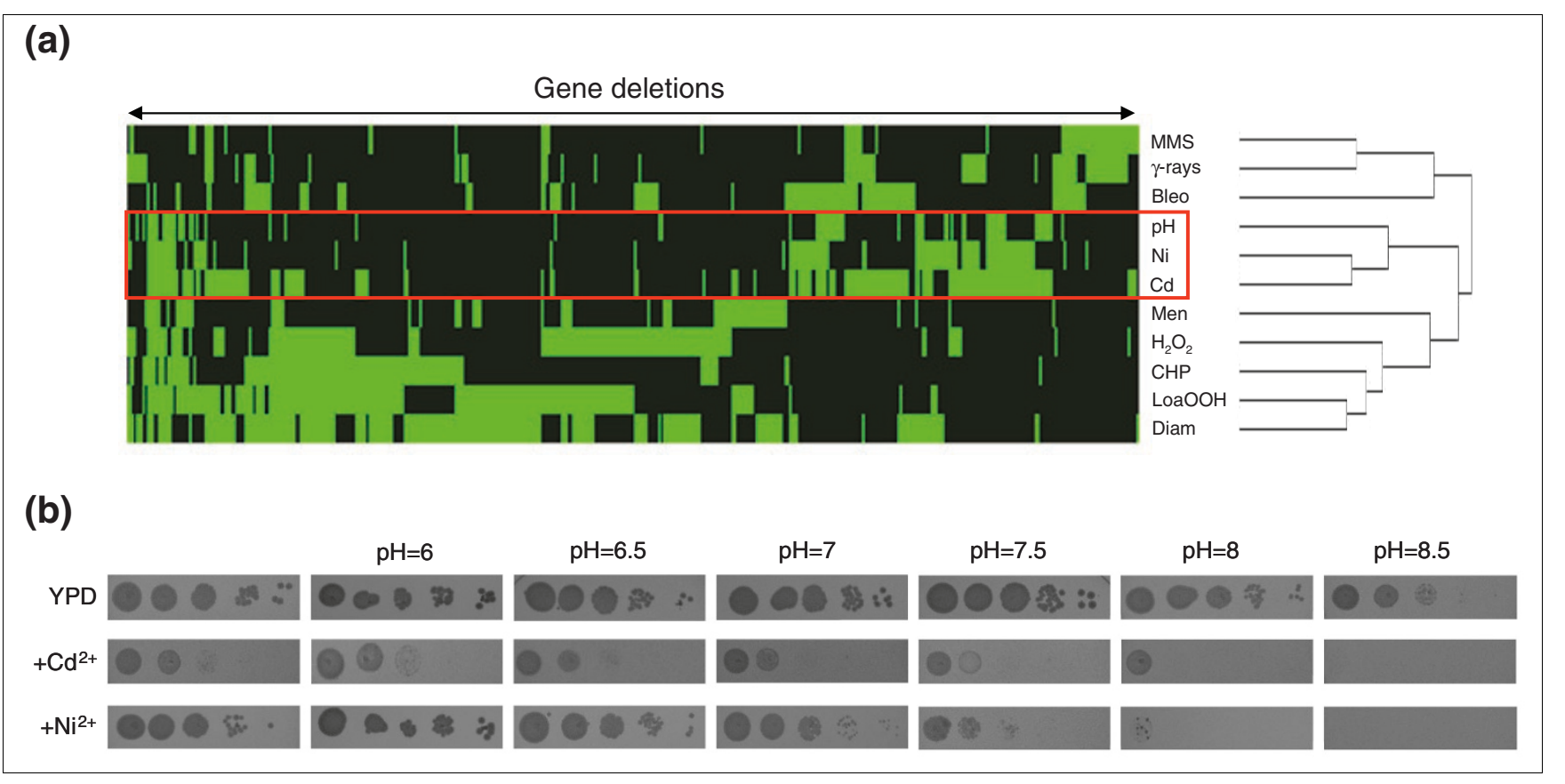

\section{Figure 3}

Cross-comparison with other stressors. (a) Hierarchical clustering of cadmium and/or nickel sensitivity-conferring mutations with the mutant sensitivity profiles of other stressors [4I-45]. The x-axis corresponds to gene deletions and the $y$-axis indicates the various stressors; mutant strains exhibiting either an enhanced sensitivity or no phenotype are shown in green and black, respectively. Nonmetal stressors were selected from previous genomic phenotyping screens conducted on the deletion mutant collections: methyl methane sulfonate (MMS), $\gamma$-radiation $(\gamma$-rays), bleomycin (Bleo), alkaline pH $(\mathrm{pH})$, menadione (Men), hydrogen peroxide $\left(\mathrm{H}_{2} \mathrm{O}_{2}\right)$, cumene hydroperoxide (CHP), linoleic acid I3-hydroperoxide (LoaOOH), and diamide (Diam). Mutant strains were hierarchically clustered with EPCLUST (average linkage, uncentered correlation [104]); only mutants sensitive to at least two different stressors were taken into account for this analysis. (b) Serial dilution assays (tenfold increments from left to right, starting from an optical density at 600 $\mathrm{nm}\left[\mathrm{OD}_{600}\right]$ of I.0) of wild-type cells grown in the absence (upper row) or in the presence of cadmium or nickel, on either standard yeast extractpeptone-dextrose (YPD) medium or on the same medium buffered at the indicated $\mathrm{pH}$ values (see 'Materials and methods' for details).

alternative possibility is nickel competition at the level of iron-regulated enzymes, as reported for various Fe-S (for example, aconitase and succinate dehydrogenase) and other iron-dependent enzymes in mammalian cells [59].

Other iron-related genes whose mutation makes cells specifically sensitive to nickel or cadmium are Ccc2 (a P-ATPase responsible for copper loading of the Fe [II] oxidoreductase Fet3) and Smf3 (a divalent metal transporter that mobilizes iron ions from the vacuole to the cytosol under conditions of iron deficiency). Mutations affecting the human orthologs of these genes respectively cause Wilson disease (characterized by abnormal copper accumulation in liver) [60] and microcytic anemia with hepatic iron overload [61] (Additional data file 2).

\section{Metal-resistant mutants}

A total of 46 mutants, not considering the 45 strains that were nickel resistant but cadmium sensitive (Figure 1a; also see the next section), exhibited increased resistance to cadmium (20 mutants, six of which were in uncharacterized ORFs), nickel (11 mutants), or both metals (15 mutants, three of which were in uncharacterized ORFs; see also Additional data file 2). The latter mutants include the transcriptional repressor Rim101 plus seven genes encoding proteins involved in the proteolytic activation and/or functionality of this regulator (Figure 5a). Originally identified as a regulator of meiotic gene expression and sporulation [62], Rim101 has also recently been implicated in the control of cell wall assembly and as a determinant of monovalent cation and alkaline $\mathrm{pH}$ tolerance [63-65]. Although conclusive evidence on the functional relationship between activated Rim101 and cell wall construction is still lacking, recent DNA microarray data have shed light on the transcriptional targets of Rim101. These include the transcription factors $N R G 1$ and $S M P 1$, which themselves act as repressors of functionally heterogeneous sets of genes [64]. To gain insight into Rim101 targets that are more closely related to cadmium/nickel resistance, we over-expressed both repressors and tested metal tolerance of the resulting transformants. As shown in Figure $5 \mathrm{~b}$, an increase in cadmium/nickel tolerance was observed in strains overexpressing Nrg1 but not Smp1, thus pointing to the former repressor as a downstream effector of the metal resistance phenotype brought about by Rim101 deletion. Among the targets of Nrg1 [66] is the low-affinity Trp/His transporter encoded by the TAT1 gene, whose deletion also enhances cadmium/nickel tolerance (Figure 5c). In addition, when tested with the fluorescent nickel chelator Newport Green [21], both 


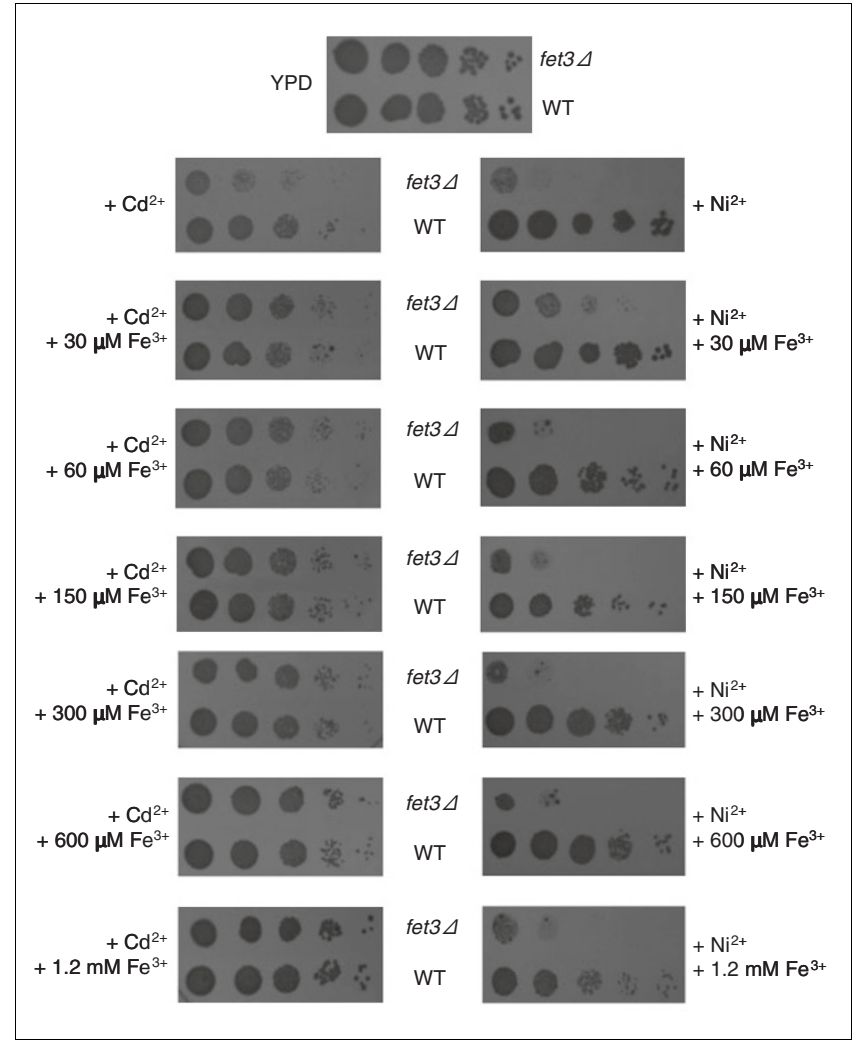

\section{Figure 4}

Effect of iron supplementation on cadmium and nickel tolerance. Serial dilution assays comparing the iron uptake impaired deletion mutant strain fet3 $\Delta$ and wild-type (WT) cells grown in the presence of cadmium (40 $\mu \mathrm{mol} / \mathrm{l})$ or nickel $(2.5 \mathrm{mmol} / \mathrm{l})$ and supplemented with the indicated concentrations of $\mathrm{FeCl}_{3}$. A no-metal control is shown at the top; similar results (not shown) were obtained with a strain deleted in FTRI, the other component of the Fet3/Ftr I high-affinity iron uptake system. YPD, yeast extract-peptone-dextrose.

rim101 $\Delta$ and tat1 $\Delta$ mutants exhibited strikingly reduced nickel accumulation (Figure $5 \mathrm{~d}$ ). We thus propose that Tat 1 is a novel entry route for nonessential metals in yeast. Interestingly, mammalian orthologs of Tat1 encode similarly promiscuous transporters that are involved in high-affinity cationic amino acid transport but also serve as receptors for various ecotropic retroviruses such as murine leukemia virus [67].

Other transporter mutants exhibiting cadmium (but not nickel) resistance include $s m f 2 \Delta$, an intracellular manganese transporter [52] (see also Figure 7), and zrt3 $\Delta$, which is a transporter that mobilizes zinc ions from the vacuole to the cytoplasm [68]. Additional mutants of this kind are disrupted in the vacuolar transporter chaperones Vtc4 (nickel/cadmium resistant) and Vtc1 (nickel resistant), both of which have previously been reported to cause manganese resistance when deleted [69]. Also notable among the genes that when deleted cause cadmium and/or nickel resistance are Sif2, a subunit of the Set3C histone deacetylase complex whose disruption increases telomeric silencing, the cell cycle regulators

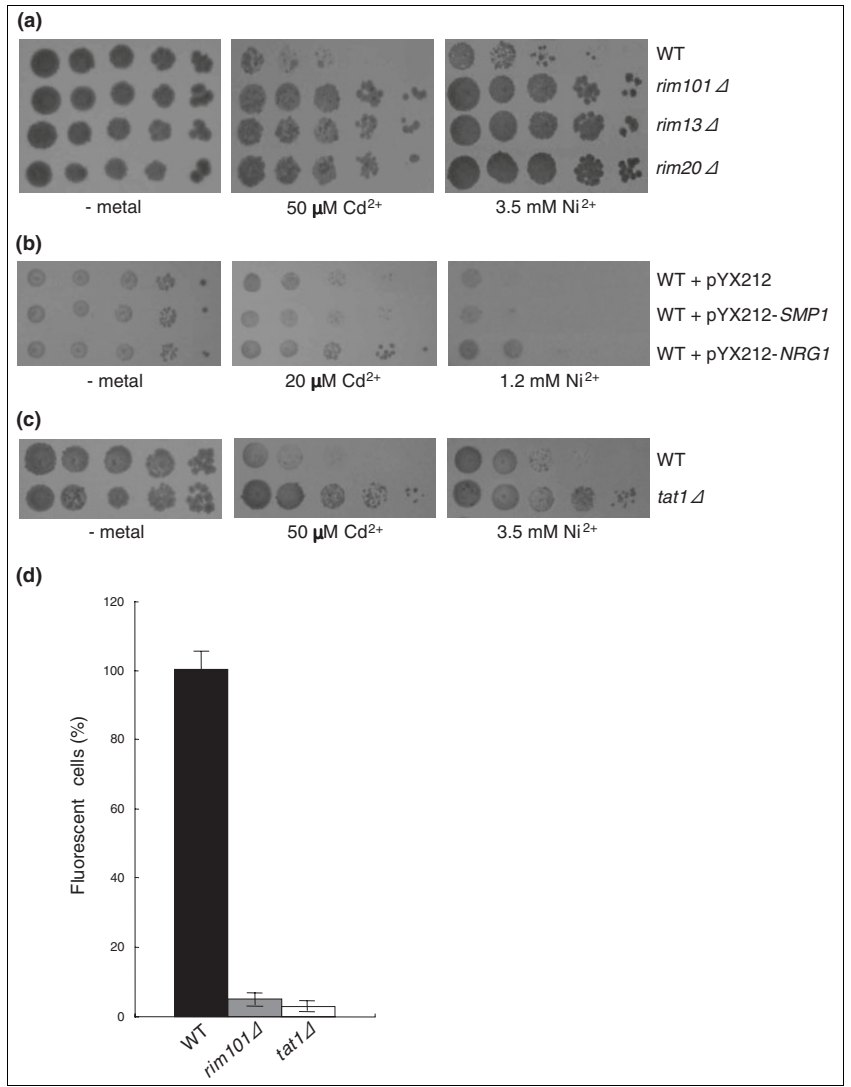

Figure 5

Rim IOI-mediated metal resistance. (a) Serial dilution assays documenting the cadmium and nickel resistance of rim $101 \Delta$ and of representative Rim I0I-related mutants. Wild-type (WT) and mutant strains were grown in the absence of exogenously supplied metals or in the presence of the indicated concentrations of cadmium and nickel. (b) Over-expression of $\mathrm{Nrg}$ I, but not Smpl (two transcription factors negatively regulated by Rim IOI), enhances tolerance to both cadmium and nickel compared with WT cells. Scaled down concentrations of cadmium and nickel were utilized for these assays, which were conducted under selective, synthetic dextrose medium conditions. (c) Increased cadmium/nickel tolerance of a strain disrupted in TATI, a membrane transporter negatively regulated by $\mathrm{Nrg}$ I. (d) Intracellular nickel accumulation by WT, rim IOI $\Delta$, and tat I $\Delta$ cells analyzed by Newport Green staining (see 'Materials and methods' for details); the percentage of fluorescent cells (average \pm standard deviation of three independent experiments) is expressed relative to WT (100\%).

Cln3 and Sap19o, and the mitogen-activating protein kinase cascade regulator Sis2.

\section{Mutations in the ESCRT and in the endosome-to-Golgi retromer complexes differentially affect cadmium and nickel tolerance}

As was anticipated (Figure 1), mutations in 45 genes, more than half of which had never previously been implicated in metal tolerance, oppositely affect cadmium and nickel toxicities, making cells more sensitive to cadmium while increasing nickel tolerance. As shown in Figure 6a (also see Table 1 and Additional data files 3 and 4), 70\% of these genes are involved in protein traffic to and formation of the prevacuolar compartment (PVC; pathway I; 20 mutants), and in protein 
retrieval from the PVC to the late Golgi (pathway II; ten mutants). Some of these mutants, belonging to pathway I, were previously shown to be cadmium sensitive [52,70-72] or nickel resistant [73], whereas seven pathway II mutations, only one of which known to cause cadmium sensitivity, were found to increase nickel tolerance [74]. Newly identified pathway I mutants include all class $\mathrm{E}$ vps components of the 'endosomal sorting complexes required for transport' (ESCRT I, II and III) [75,76]. Pathway II mutants are comprised of genes involved in protein retrieval to the Golgi, including all components of the 'retromer complex' and other functionally related proteins such as Vps3o and the phosphatidylinositol-3P binding nexin Snx3 [77,78]. Representative phenotypes of mutants affected in these pathways, which are conserved from yeast to humans, are shown in Figure 6b. Targeting to the PVC and formation of the 'multivesicular body' by the ESCRT pathway are involved in clearance of misfolded membrane proteins, downregulation of plasma membrane receptors and transporters, localization and processing of vacuolar components, and removal of selected regions of the plasma membrane, coupled with ingestion of surrounding small molecules, through 'fluid phase endocytosis' [75,76,79]. Pathway II, instead, is responsible for recycling hydrolase receptors and other vacuolar traffic components from the PVC to the late Golgi and to the plasma membrane [77,80,81]. Mutational inactivation of these pathways can lead, for instance, to an abnormal accumulation of plasma membrane transporters that may promiscuously internalize toxic metals (I), or to protein missorting and impaired vacuole functionality, including metal detoxification (II). Both scenarios readily apply to and explain cadmium sensitivity. This metal, in fact, is taken up and mobilized through Smf1 and Smf2 [52,82], two membrane transporters that are downregulated via the ESCRT and whose over-expression increases cadmium toxicity (Figure 7). On the other hand, cadmium is known to be detoxified by vacuolar components such as the glutathione Sconjugate transporter Ycf1, disruption of which specifically impairs cadmium tolerance [10]. Thus, a cadmium sensitivity phenotype is also expected for mutations interfering with proper sorting of these components (for example, Ycf1) or with retrieval from the PVC to the Golgi of receptors that mediate the trafficking of other components required for vacuole biogenesis and functionality.

Less straightforward is the relationship between mutations in the same set of genes and resistance to nickel (outlined in Figure 6a), a metal that is also subjected to vacuolar detoxification ([83] and the present data; for example see Figure 2), but whose mechanisms of internalization (and export) are still largely unknown. As shown in Figure 8a (but also see Eide and coworkers [84]), pathway I mutants all exhibit a markedly reduced nickel accumulation, suggesting that export and/or reduced uptake may underlie the nickel resistance displayed by these mutants. Potential candidates for this role are transporters (or transport-related proteins) such as Smf1 and Pho88, which are known to interact with one or more components of pathway I $[52,85]$ and that cause nickel sensitivity when disrupted (Additional data file 3). To test this hypothesis we assayed the nickel tolerance of the corresponding over-expressing strains, which was increased in the case of Pho88, but not Smf1 (Figure 8b). This points to an as yet unidentified role of Pho88 in nickel tolerance. It is possible, however, that other uptake systems impaired in ESCRT mutants (for example, fluid-phase endocytosis) as well as missorting to the plasma membrane of an as yet unidentified metal exporter may also contribute to nickel tolerance. Indeed, among mutations causing nickel specific resistance is Siw14, a tyrosine phosphatase that is involved in actin filament organization, whose disruption leads to a defective fluid phase endocytosis [86].

A different mode of action probably applies to the expanded set of retromer-related mutants that we also identified as nickel resistant (see pathway II in Figure 6a). One of these mutants (vps54) was previously reported to have a nickel uptake capacity similar to that of WT in intact cells, but a threefold higher uptake rate after plasma membrane permeabilization [74]. Based on these observations, it was proposed that in this particular vps mutant an unidentified late Golgi $\mathrm{Mg}^{2+} / \mathrm{H}^{+}$exchanger could be missorted to the vacuole, where it would promote enhanced nickel accumulation (and detoxification). At variance with this hypothesis, we found that only a small fraction of cells mutated in various retromer-related components were able to accumulate nickel (as revealed by Newport Green fluorescence), whereas most cells were not fluorescent and thus apparently unable to accumulate nickel ions (Figure 8c). Whether this is due to a reduced uptake or to an enhanced export of nickel is not known at present. It should be noted, however, that defects in this particular traffic network can cause protein missorting to the vacuole, but also to the plasma membrane [81,87-89]. It is thus conceivable that avoidance and/or extrusion of nickel by a divalent cation transporter (or exchanger) mislocalized to the plasma membrane might be responsible for the increased nickel tolerance of these mutants. The opposite situation holds for two plasma membrane located uracil and nicotinic acid transporters, Fur4 and Tna1, which when deleted cause nickel resistance along with reduced intracellular nickel accumulation, and for which we propose a promiscuous role in nickel internalization (Additional data file 6).

Other cadmium-sensitive/nickel-resistant strains are mutated in amino acid metabolism enzymes (for example, Aat2 and Aro2) and nuclear components (for example, Mog1, Nnf2, Spt7, and Srb8), including the putative catalytic subunit of a class II histone deacetylase (Hda1), as well as in the uncharacterized ORF YILO39W. Also noteworthy are mitochondrion defective mutants, one of which (mam3 4 ) was previously reported to be cadmium sensitive, but resistant to cobalt and zinc [90]. 


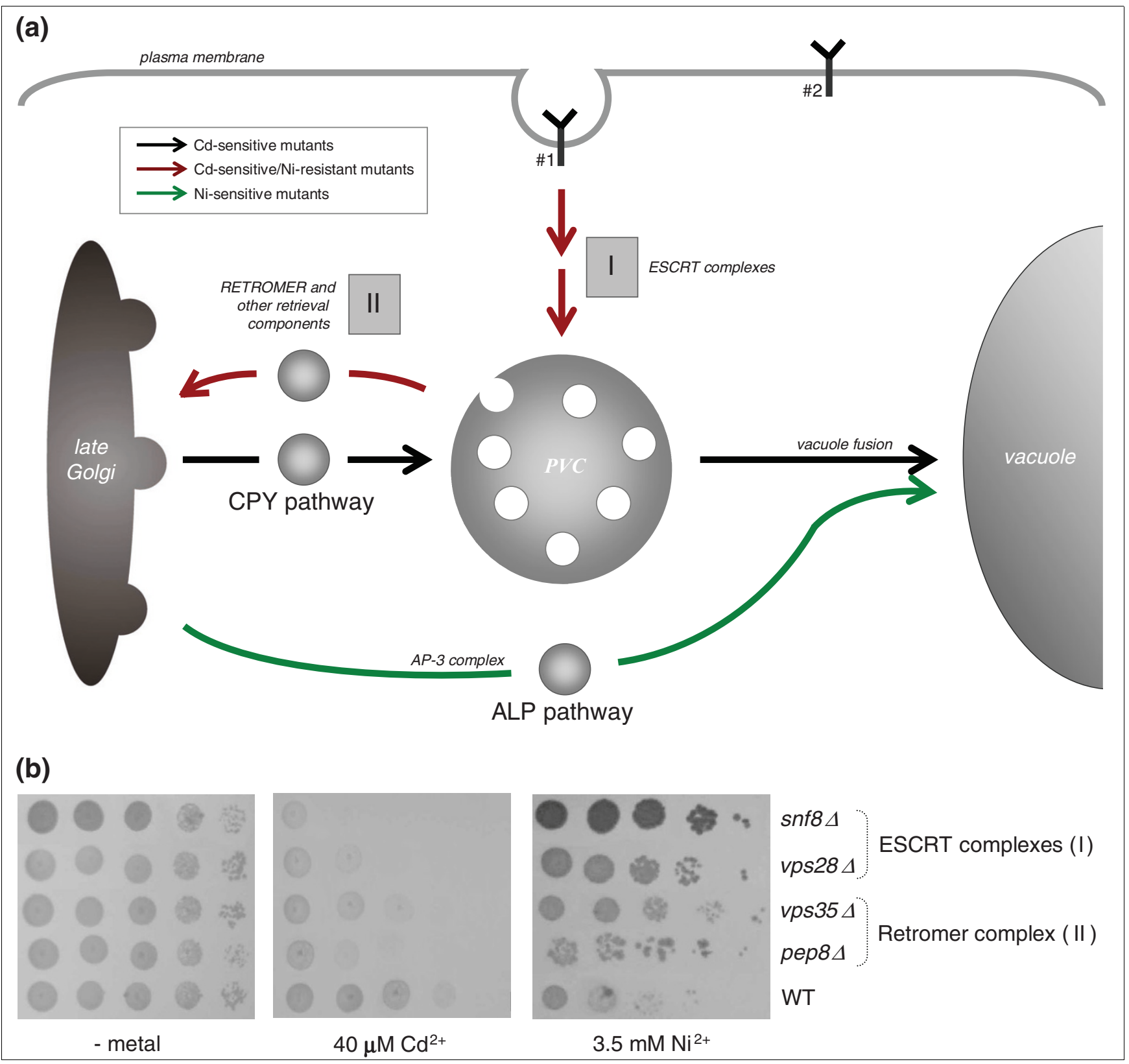

\section{Figure 6}

Cadmium sensitive/nickel resistant mutants and protein traffic networks centred on the vacuole and the Golgi. (a) Schematic representation of the endocytotic pathway, including targeting to (and formation of) the prevacuolar compartment (PVC; pathway I), and protein retrieval from the PVC to the late Golgi (pathway II). The Golgi-to-vacuole, carboxypeptidase Y (CPY) and alkaline phosphatase (ALP) pathways that, when disrupted, respectively lead to cadmium and nickel sensitivity are shown for comparison. Pathways whose disruption determines cadmium sensitivity but nickel resistance are indicated with red arrows; and pathways that cause cadmium or nickel specific sensitivity when disrupted are indicated with black and green arrows, respectively. The Y-shaped symbols indicate plasma membrane transporters whose deletion causes cadmium (\#I; for example, Smfl) or nickel (\#2; for example, Fur4 and Tnal) resistance; see Additional data file 2 for further details on the genes that are involved in these pathways. (b) Serial tenfold dilutions of mutant strains representative of pathway I and II assayed for their capacity to grow onto yeast extract-peptone-dextrose (YPD) plates supplemented with the indicated cadmium and nickel concentrations; the wild-type (WT) control strain is shown at the bottom of each panel.

\section{Cellular toxicity signatures of other metals}

As a last step in our analysis, we considered the extent to which the range of genes and pathways that, when disrupted, affect cadmium/nickel tolerance overlaps that of other metals. To this end, the entire set of sensitive and resistant mutant strains was exposed to sublethal concentrations of four additional metals with varying degrees of chemical (and/ or biologic effect) similarity to cadmium and nickel, plus the metalloid $\mathrm{AsO}_{2}{ }^{-}$. As shown by the clustering analysis in Figure 9, which does not include 67 cadmium-specific and nine 


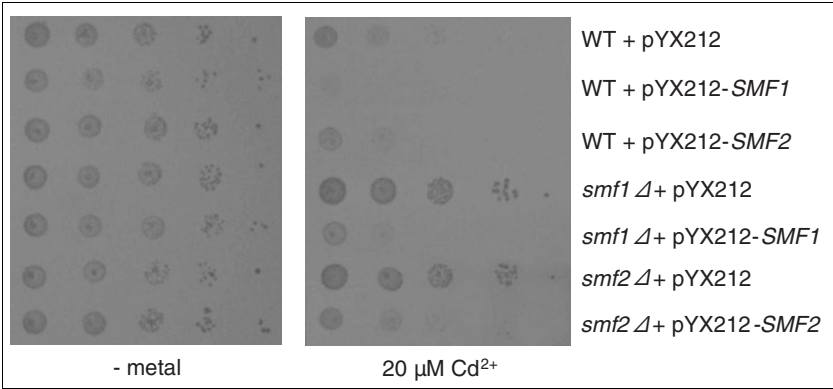

Figure 7

Smf transporters and cadmium toxicity. Serial dilution plate assays (synthetic dextrose medium) comparing the cadmium tolerance of SMFI and SMF2 disrupted or overexpressing strains as indicated. Wild-type (WT) cells transformed with the empty PYX2I 2 vector served as controls for these experiments; a no-metal control is shown in the left panel.

nickel-specific mutants (Additional data file 7), the overlap was higher for sensitivity-conferring than for resistance-conferring mutations, and various pathways involved in multimetal sensitivity could be identified.

The closest resemblance with cadmium was observed for mercury, a highly toxic, thiophilic group IIb metal with a nearly identical atomic radius. This is followed by arsenite, which despite its chemical dissimilarity is known to bind thiols (especially dithiols [91]) and to share various cellular toxicity similarities with cadmium [32]. The most prominent divergence between cadmium and arsenite pertains to the Rim101 pathway (which when disrupted causes $\mathrm{AsO}_{2}^{-}$sensitivity but resistance to cadmium, nickel and zinc) and to a few mutants (which exhibited the opposite phenotypic response, such as erv $41 \Delta$ and erv464). Interestingly, the same metal discrimination capacity applies to the Rim101/Nrg1-regulated plasma membrane transporter Tat1, whose disruption leads to resistance to cadmium, nickel and zinc, but not arsenite.

The phenotypic overlap between nickel and cobalt was not as high as one might have expected based on their chemical similarity. Especially noteworthy is the increased sensitivity to cobalt and to all the other tested metals, except nickel, exhibited by ESCRT pathway mutants, and the only partial overlap between nickel and cobalt observed for retromer mutants. Also worthy of note are the different metal tolerance phenotypes associated with the Fur4 and Tna1 transporters, whose deletion causes sensitivity to cadmium and to other metals, but nickel resistance (see Additional data file 6 for representative phenotypes). One of them (Tna1) causes resistance to both nickel and cobalt when disrupted, whereas deletion of the other transporter (Fur4) makes cells resistant to nickel and zinc but not cobalt. Conversely, disruption of the Smf1 transporter as well as disruption of various components of the Adaptor Protein complex AP-3 involved in the ALP pathway (Table 1 and Additional data file 3) causes nickel but not cobalt sensitivity.

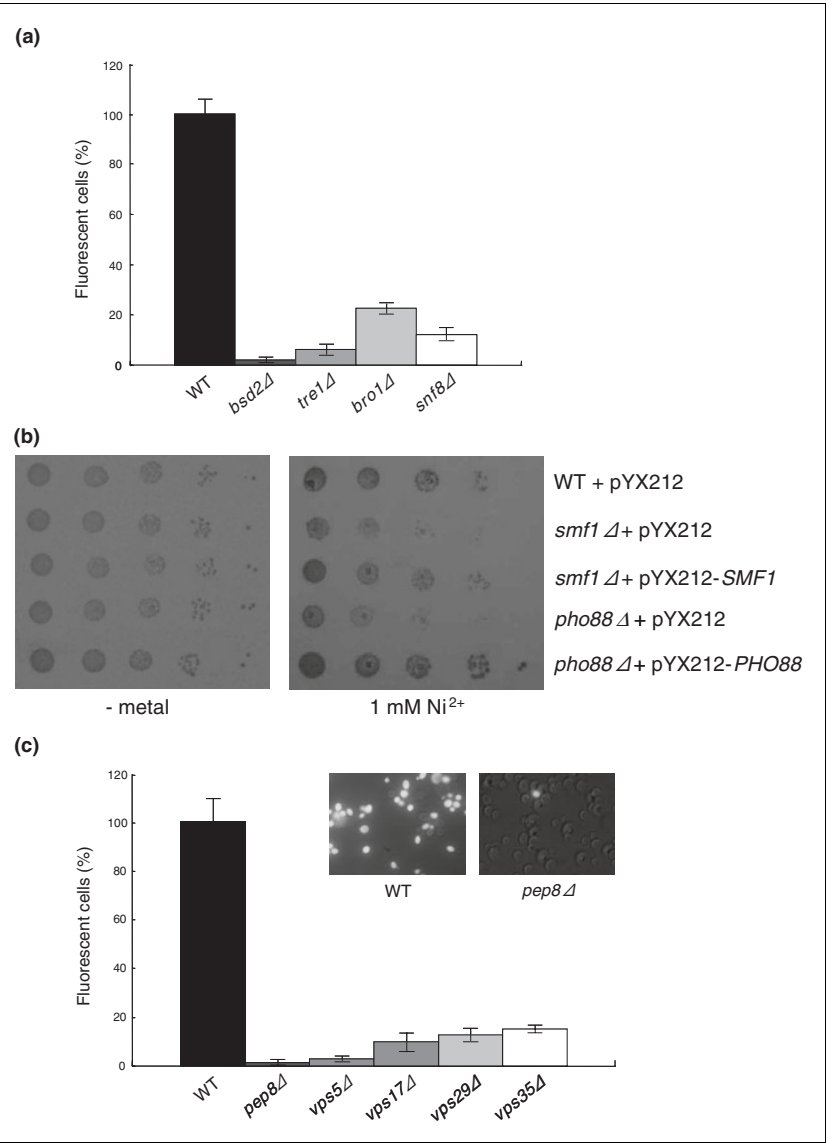

Figure 8

Enhanced nickel tolerance of endocytotic and retromer pathway mutant strains. (a) Nickel accumulation by wild-type (WT) and pathway I mutant strains (see Figure 6a). The indicated mutants were exposed to $\mathrm{NiCl}_{2}(\mathrm{I}$ $\mathrm{mmol} / \mathrm{l})$, treated with Newport Green, and visualized using fluorescence microscopy (see 'Materials and methods'). The percentage of fluorescent cells (average \pm standard deviation of three independent experiments) is expressed relative to wild-type (WT; 100\%). (b) Enhanced nickel tolerance of the Pho88 over-expressing strains. Serial dilution assays comparing the nickel tolerance of $\mathrm{smfl} \Delta$ and pho88 $\Delta$ strains transformed with the empty $\mathrm{PYX} 2 \mathrm{I} 2$ vector or with the same vector bearing the SMFI or the PHO88 coding sequences. (c) Nickel accumulation by WT and the indicated retromer-related (pathway II) mutant strains analyzed by Newport Green staining as in panel a; representative images of WT and mutant cells (100x magnification) are shown in the insets.

As predicted by the protective effect exerted on both WT and mutant cells (Figure 4) and by its 'hard' Lewis acid nature, Fe(III) was the most divergent of the metals investigated. Also apparent in Figure 9 is that under conditions of iron sufficiency, mutations in genes belonging to the iron regulon cause increased sensitivity to all of the examined metals except iron itself. This suggests that, albeit with different mechanisms, toxic metal-induced iron depletion may be a common feature of many (if not all) toxic metals. Zinc and Fe(III), both of which are essential metal ions, clustered together despite their chemical dissimilarity. On the whole, however, we find a fairly close overlap between the chemical properties and the cellular toxicity signatures of the various 


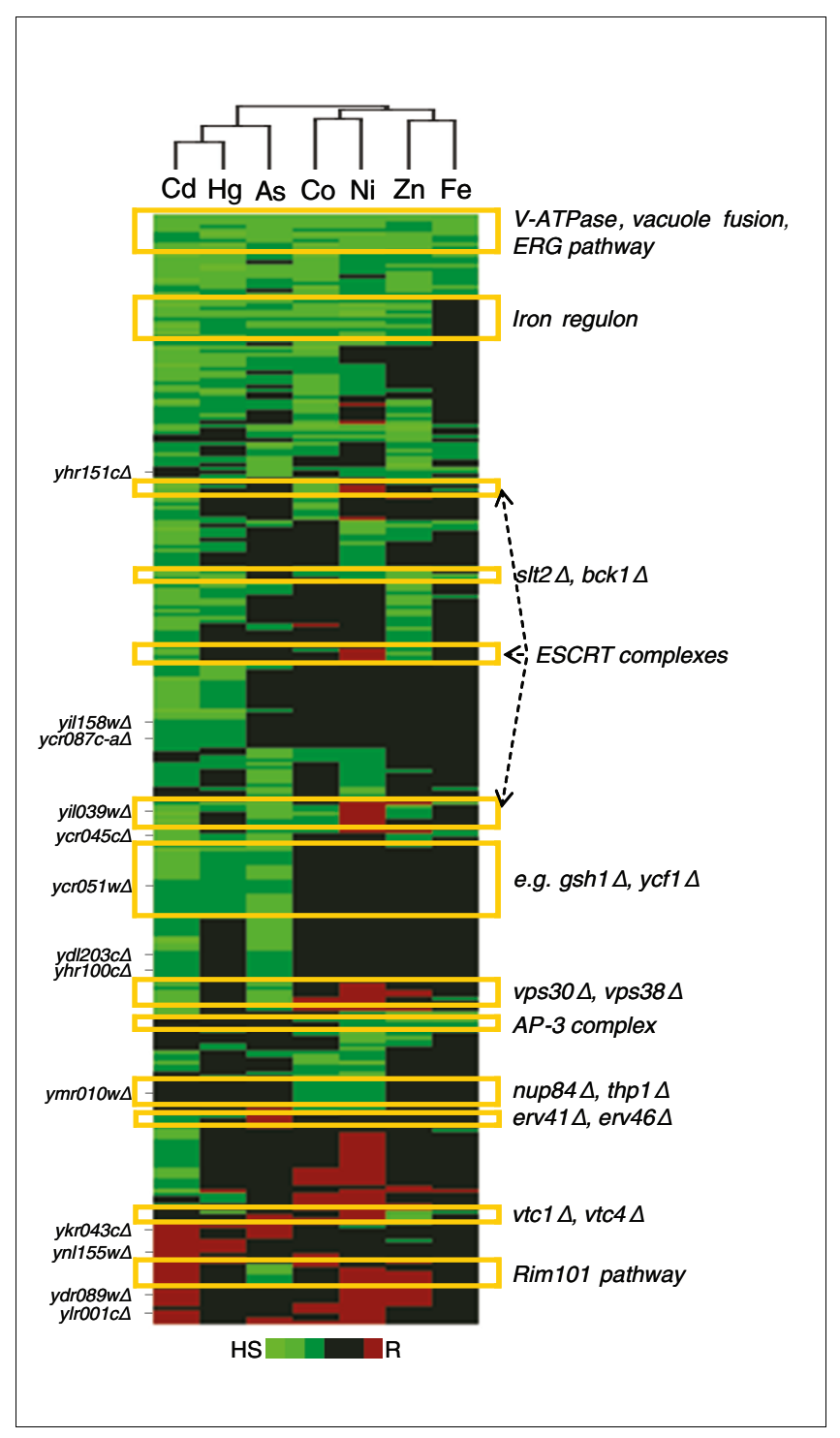

\section{Figure 9}

Multimetal toxicity signatures. Hierarchical clustering of cadmium and nickel tolerance-modulating mutations with the phenotypic profiles of other metals. Cadmium/nickel sensitive or resistant strains were exposed in triplicate to $\mathrm{HgCl}_{2}(190 \mu \mathrm{mol} / \mathrm{l}), \mathrm{NaAsO}_{2}(1.5 \mathrm{mmol} / \mathrm{l}), \mathrm{CoCl}_{2}(2 \mathrm{mmol} /$ I), $\mathrm{ZnCl}_{2}(18 \mathrm{mmol} / \mathrm{l})$, and $\mathrm{FeCl}_{3}(15 \mathrm{mmol} / \mathrm{l})$, followed by serial dilution assay verification of mutations affecting cell tolerance to this expanded set of metals (see 'Materials and methods' for details). The $\mathrm{x}$-axis corresponds to the metals examined, and the $y$-axis indicates gene deletions. Mutants exhibiting either an enhanced sensitivity or resistance, or no phenotype are represented in green, red and black, respectively. Metal tolerance (from 'high sensitivity' [HS] to 'resistance' [R]) of the different mutant strains is indicated in a false color scale; only strains sensitive or resistant to at least two metals are shown (see Additional data file 7 for the entire database of multimetal phenotypes). Hierarchical clustering analysis was performed with EPCLUST, as specified in the legend to Figure 3, leaving out 67 cadmium-specific and nine nickel-specific gene mutations (listed in Additional data file 7). Representative genes and pathways affecting multimetal tolerance as well as a subset of co-clustering uncharacterized open reading frames with orthologous sequences in other organisms (see Additional data file 2) are indicated on the right-hand and left-hand, respectively. metals. For example, clustering based on the phenotypic profiles of a selected subset of mutants fits with chemical properties such as the ability of the various metals to form insoluble sulfides in a strongly acidic environment, which is shared by cadmium, mercury and As(III), but not nickel, cobalt, zinc, or Fe(III). As further shown in Figure 9, multimetal phenotypic profiling also allowed to annotate various ORFs, some of which are homologous to disease-related human genes. For instance, YCR045C and YCRo51W are homologous, respectively, to Pcsk9 and Tnks2. Pcsk9 is an endoplasmic reticulum serine protease that is involved in an autosomal dominant form of hypercholesterolemia [92], a disease that is also induced by dietary metal imbalance [93]; Tnks2 is a cytosolic member of the poly(ADP)ribose polymerase family, whose over-expression affords cytoprotection by preventing excessive poly(ADP)ribose polymerase activation and NAD depletion after exposure to DNA-damaging agents [94].

\section{Conclusion}

As revealed by this study, which interrogated all nonessential genes of $S$. cerevisiae for their role in modulating metal toxicity, 16 functional subnetworks (comprised of 207 genes, at least half of which had never been implicated in metal tolerance previously) negatively influence cadmium and/or nickel tolerance when disrupted. Core genes influencing cadmium and nickel tolerance were mapped to nine subnetworks, a subset of which (for example, V-ATPase, vacuole fusion, and the ERG pathway) cause enhanced co-sensitivity to mercury, arsenite, cobalt, zinc and iron, thus pointing to the occurrence of multimetal defense systems in yeast. Seven of these subnetworks were expanded to include additional mutations specifically associated with cadmium and/or nickel sensitivity, along with six additional subnetworks causing metal-specific (especially cadmium-specific) sensitivity (Table 1). Only one of the latter subnetworks (with a bearing on the ALP branch of the Golgi-to-vacuole traffic pathway) was found to be specifically involved in nickel tolerance, as opposed to five subnetworks causing cadmium-specific sensitivity when disrupted. Thus, cadmium is not only more toxic than nickel, but it also has a broader spectrum of cellular processes that directly or indirectly contribute to its detoxification. Most prominent among these processes are those related to vesicular protein traffic (including the endocytotic pathway and a different branch of the Golgi-to-vacuole traffic), antioxidant defense, and DNA repair. The latter, in particular, further strengthens the causal relationship between cadmium genotoxicity and DNA repair [6]. In fact, although cadmium and nickel have both been recognized as human carcinogens [2,3], mutagenic activity appears to be a distinguishing feature of cadmium $[1,4]$. Nickel, instead, is a weak mutagen with a marked nuclear tropism, whose carcinogenicity is thought to primarily rely on unprogrammed chromatin modification [5]. It is interesting to note in this regard that the nuclear pore complex is one of the few core subnetworks enriched in nickel-specific sensitive mutants. Also interesting is that 
three out of eight mutants specifically resistant to nickel (but unrelated to vesicular traffic; Additional data file 7) are deleted in genes encoding distinct chromatin modification enzymes ( $H D A 1, E A F 7$, and $S P T_{7}$ ) and one is deleted in a Ran homolog of the Ras GTPase family (MOG1) that is involved in protein traffic through the nuclear pore.

Many metal toxicity-modulating pathways are related to metal damage prevention or repair, whereas others appear to play a more general (and indirect) role in promoting cell survival/recovery under stress conditions. Especially noteworthy among the latter are mRNA decay and nucleocytoplasmic transport, two processes that to our knowledge have not previously been implicated in metal tolerance and that might explain the variety of putative target genes previously identified as cadmium stress responsive [11]. Their identification among metal sensitivity-conferring mutations suggests that not only the clearance of damaged (or unwanted) proteins by the proteasome and transcriptional regulation, but also mRNA turnover and relocalization are important for translational/metabolic reprogramming under conditions of metal stress. Interestingly, coordinate downregulation of iron-related proteins mediated by mRNA degradation under iron starvation conditions [95] as well as mRNA mistranslation after chromium exposure [96] have recently been described in yeast. The fact that structurally diverse yet functionally related gene products cause metal sensitivity when disrupted provides strong evidence that the cellular processes represented in specific subnetworks play an important role in preventing or repairing metal-induced cell damage. However, this does not exclude the possibility that a subset of the mutant strains that we have identified as metal sensitive are due to chemical-genetic synthetic lethality resulting from direct attack (and inactivation) of a functionally related protein target by the metal. Mutations associated with this kind of metal-induced lethality are likely to be enriched in the genes we classified as 'solitary'.

Among the unrelated stressors we examined, alkaline $\mathrm{pH}$ emerged as the most closely related to cadmium/nickel stress. This genomic phenotyping resemblance was traced back to iron deficiency, which - albeit with different mechanisms - is caused by both cadmium and nickel and appears to be a fairly general effect of metal toxicity (Figure 9). Broadrange transporters were identified as the most proximal effectors of iron deficiency-related and other kinds of altered metal tolerance. The latter include Tat1, which is a low-affinity Trp/His transporter negatively regulated by Nrg1 [66], which emerged from this study as one of the downstream effectors of the multimetal resistance caused by disruption of the Rim101 pathway. Toxic metal internalization (or abnormal intracellular mobilization) thus appears to be one of the most general and detrimental effects caused by transporter promiscuity, a trait that has probably evolved as a way to deal with multiple nutritional deficiencies under nutrient limiting (but toxic metal-free) conditions. This provides novel mecha- nistic support to the notion that nutrient limitation (especially iron and copper, but also amino acids and vitamins) may aggravate metal toxicity in malnourished human populations. Another outcome of this study was the identification of 24 uncharacterized ORFs that are involved in metal tolerance, which lend themselves as novel candidate genes that are worthy of further investigation.

Systematic comparison of the cellular toxicity signatures of cadmium and nickel with those of five additional metals revealed significant overlap between their chemical and cellular toxicity properties. However, it also uncovered an unexpected degree of metal specificity, especially regarding mutations that cause resistance to nickel but sensitivity to most other metals. The hot spots for such mutations were mapped to the ESCRT and the retromer complexes, thus pointing to the ability of these pathways to discriminate between otherwise similar metals and to the potential use of selected toxic metals (for example, cadmium and nickel) as chemical probes of intracellular traffic functionality.

\section{Materials and methods \\ Yeast strains and culture conditions}

The strains used in this study derive from the $S$. cerevisiae Genome Deletion Project [18]. They were purchased from Open Biosystems (Huntsville, AL, USA) and converted into a 384-well plate format by manual multipinning. Deletion of individual nonessential genes (or ORFs) were in the MAT $\alpha$ BY4742 background, except for 79 strains with a MAT $\alpha$ BY4739 parental background. Untagged deletion strains utilized for phenotype verification were in the parent MAT $\alpha$ BY4741 background and were obtained from EUROSCARF (Frankfurt, Germany). Cells were grown at $30^{\circ} \mathrm{C}$ on yeast extract-peptone-dextrose (YPD) or synthetic dextrose medium (supplemented with leucine, lysine, and histidine, but without uracil), as indicated. For some experiments, YPD was supplemented with $\mathrm{FeCl}_{3}$ or adjusted to $\mathrm{pH}$ values ranging from 6 to 8.5 with the addition of $50 \mathrm{mmol} / \mathrm{l} \mathrm{MOPS}$ (3- [4-morpholino]propane sulfonic acid) or TAPS (N[tris(hydroxymethyl)methyl]-3-aminopropanesulfonic acid), as specified in the text.

\section{Metal tolerance screening}

A total of 4,688 single gene deletion mutants, not including 90 strains that failed quality control and 48 slow-growth strains previously shown to exhibit a high false-positive rate [97], were utilized for genomic phenotyping. Metal titrations coupled with serial dilution spot assays (starting from cultures pregrown in YPD at an optical density at $600 \mathrm{~nm}$ $\left[\mathrm{OD}_{600}\right]$ of 1.0 and diluted up to 10,000 fold in tenfold increments before spotting; see below) were initially carried out in the parent WT strains to determine metal concentrations, allowing for about $90 \%$ of control ('minus metal') growth after 48 hours. These concentrations ranged from 40 to 60 $\mu \mathrm{mol} / \mathrm{l}$ and from 2.5 to $4.5 \mathrm{mmol} / \mathrm{l}$ for cadmium and nickel, 
respectively. Metal concentrations for genomic phenotyping were further refined in pilot experiments carried out with an arrayed test set of 384 strains, including the WT strains plus two known cadmium-sensitive mutants (yap1 $\Delta$ [7] and ycf1 $\Delta$ [10]) and one nickel-sensitive mutant (pep5 4 [98]) as positive controls. Optimal concentrations of $50 \mu \mathrm{mol} / \mathrm{l}$ cadmium and $2.5 \mathrm{mmol} / \mathrm{l}$ nickel were thus determined and utilized for the screening.

To this end, individual plates from the deletion strain collection (384-well format master plates with eight empty wells as contamination controls) were inoculated into $150 \mu$ liquid YPD plus $200 \mu \mathrm{g} / \mathrm{ml} \mathrm{G} 418$ (GIBCO-Invitrogen, Carlsbad, CA, USA) using a 384-pin tool (VP 384F; V\&P Scientific Inc., San Diego, CA, USA). After 2 days at $30^{\circ} \mathrm{C}$, cells were replica inoculated onto YPD-agar without G418, supplemented or not supplemented with the appropriate metal. This was done with the use of a library copier (VP 381 ; V\&P Scientific Inc.) by touching the bottom of the wells and then raising and lowering the multipin replicator three times, in order to mix the cells and obtain a properly diluted inoculum (about 500 cells/ pin). After 2 to 3 days at $30^{\circ} \mathrm{C}$, plates were examined for metal-sensitive and metal-resistant strains according to relative colony size, followed by digital image recording. A positive result was scored when colony size under metalsupplemented conditions was diminished (no growth or slow growth phenotype in the case of metal sensitivity) or augmented (overgrowth phenotype in the case of metal resistance) compared with neighboring (unaffected) strains and with the colony size of the corresponding strains grown on the 'minus metal' plate (Additional data file 1 [Figure S1A]). Five replicate screens starting from fresh liquid cultures were run for each metal (Additional data file 2 provides details on the cumulative outcome of this multireplicate screening), followed by verification of strains that were scored as sensitive or resistant in at least three screens by serial dilution spot assays (see below).

\section{Validation and multimetal assays}

Strains that were deemed as positive (sensitive or resistant) in the primary screen as well as strains consistently exhibiting an overgrowth or slow-growth phenotype in control ('minus metal') plates were individually verified by serial dilution spot assays. Mutant strains of interest were recovered from the original 96-well plates, assembled into a new plate, and cultured in YPD medium as above. After 24 hours at $30^{\circ} \mathrm{C}$, the $\mathrm{OD}_{600}$ of individual cultures was determined with a microplate reader, adjusted with YPD medium to an $\mathrm{OD}_{600}$ value of 1.0 and serially diluted in tenfold increments. Aliquots $(4 \mu \mathrm{l})$ of each dilution were spotted onto YPD-agar plates in the presence or absence of appropriate metal concentrations (40 $\mu \mathrm{mol} / \mathrm{l} \mathrm{CdCl}_{2}$ and $2.5 \mathrm{mmol} / \mathrm{l} \mathrm{NiCl}_{2}$ for sensitive strains, and $50 \mu \mathrm{mol} / 1 \mathrm{CdCl}_{2}$ and $3.5 \mathrm{mmol} / 1 \mathrm{NiCl}_{2}$ for strains scored as resistant) and growth was examined after incubation at $30^{\circ} \mathrm{C}$ for 2 to 3 days. Mutant strains exhibiting a reduction in growth at the first, second, or third (or fourth) dilution were classified as having a 'high', 'medium', or 'low' metal sensitivity (HS, MS, and LS, respectively); only one type of metalresistant phenotype was recorded (Additional data file 1 [Figures $\mathrm{S} 1 \mathrm{~B}$ and $\mathrm{S} 1 \mathrm{C}]$ ). The rate of validation of the phenotypes determined in primary screens was $85 \%$ for cadmium and 81\% for nickel. Appropriately lower metal concentrations (15 to $20 \mu \mathrm{mol} / \mathrm{l}$ cadmium and 1 to $1.2 \mathrm{mmol} / \mathrm{l}$ nickel for sensitivity and resistance, respectively) were used for assays carried out in synthetic dextrose medium (see below). Eighteen strains identified as metal-sensitive in our screen correspond to 'dubious' ORFs [99] overlapping 'bona fide' ORFs that were also found to be metal sensitive. The physical and phenotypic overlapping of this subset of ORFs is annotated in Additional data file 2, from which all redundant ORFs were removed. An additional four strains deleted in 'dubious' ORFs overlapping the 5 '-end of ORFs not present in the mutant collection were replaced with the latter ORFs and included in the final dataset. Identical screening and validation assay conditions were applied to the 388 cadmium/nickel sensitive or resistant strains that were tested with four additional metal, plus the metalloid $\mathrm{AsO}_{2}{ }^{-}$. The following concentrations, determined by metal titrations coupled with serial dilution spot assays carried out on WT cells (as described above for cadmium and nickel), were utilized: $190 \mu \mathrm{mol} / 1 \mathrm{HgCl}_{2}, 1.5$ $\mathrm{mmol} / \mathrm{l} \mathrm{NaAsO}_{2}, 2 \mathrm{mmol} / \mathrm{l} \mathrm{CoCl}_{2}, 18 \mathrm{mmol} / \mathrm{ZnCl}_{2}$, and 15 $\mathrm{mmol} / \mathrm{l} \mathrm{FeCl}_{3}$.

\section{Overexpression studies}

The Escherichia coli XL1-Blue strain was used for DNA cloning experiments. The coding sequences of the genes of interest (NRG1, PHO88, $S M F 1, S M F 2$, and $S M P 1$; see the text for further details) were obtained by polymerase chain reaction, using genomic DNA from the BY4742 strain as template and the forward and reverse oligonucleotide primers summarized in Table 2.

Individual amplicons were cloned into a modified (CpoI restriction site-containing) pYX212 vector. Following sequence verification, individual constructs were utilized for yeast transformation using the lithium acetate procedure [100].

\section{Newport Green staining}

Yeast cells were grown at $30^{\circ} \mathrm{C}$ to saturation, diluted to an $\mathrm{OD}_{600}$ of 0.3 and exposed to $1 \mathrm{mmol} / \mathrm{l} \mathrm{NiCl}_{2}$ for 18 hours. Cells were then washed three times with phosphate-buffered saline (PBS) before being incubated for 30 minutes at $37^{\circ} \mathrm{C}$ in $1 \mathrm{ml}$ PBS containing $7 \mu \mathrm{mol} / \mathrm{l}$ Newport Green DCF and 0.2\% F-127 pluronic acid (Invitrogen-Molecular Probes, Eugene, OR, USA), followed by a further 30 minutes of incubation at room temperature. After an additional wash with PBS, cells were visualized by fluorescence microscopy using a Zeiss fluorescent microscope (argon laser; $488 \mathrm{~nm}$ ). After visualization and cell counting, the fraction of fluorescent cells was determined in selected mutant strains (specified in the text) and in control WT cells. 
Table 2

\begin{tabular}{lll}
\multicolumn{2}{l}{ Oligonucleotide primers used for DNA amplification } \\
\hline Gene name & Forward/reverse & Primer \\
\hline NRGI & Forward & 5'-(CTCGGTCCGCCACCATGTTTTACCCATATAACTATAGTAAC)-3' \\
NRGI & Reverse & 5'-(CTCGGACCGTTATTGTCCCTTTTTCAAATGTGTTC)-3' \\
PHO88 & Forward & 5'-(CGCGGTCCGCTACGTAGCCACCATGAATCCTCAAGTCAGTAACATC)-3' \\
PHO88 & Reverse & 5'-(CGCGGACCGTCATTCAGCCTTAACACCAGCG)-3' \\
SMFI & Forward & 5'-(CGCGGTCCGGTTTAAACAGGCCACCATGGTGAACGTTGGTCCTTCTC)-3' \\
SMFI & Reverse & 5'-(CGCGGACCGTTAACTGATATCACCATGAGACATG)-3' \\
SMF2 & Forward & 5'-(CGCGGTCCGCTACGTAGCCACCATGACGTCCCAAGAATATGAACC)-3' \\
SMF2 & Reverse & 5'-(CGCGGACCGTTAGAGGTGTACTTCTTTGCCCG)-3' \\
SMPI & Forward & 5'-(CTCGGTCCGCCACCATGGGTAGAAGAAAAATTGAAATTGAACC)-3' \\
SMPI & Reverse & 5'-(CTCGGACCGTTAATCTGGAGAGTTTGTCGAACTCG)-3'
\end{tabular}

\section{Data analysis}

Putative human homologs were identified with BLASTP searches and through the Princeton Protein Orthology Database [101]. Information on human disease-related homologs was retrieved from the Online Mendelian Inheritance in Man database [102], the Saccharomcyes Genome Database [99], and by manual curation. Biologic processes associated with metal toxicity-modulating genes were identified and evaluated for statistical significance ( $P$-value) with the GO Term Finder program [99]. Enrichment ratios were calculated by comparing the representation of each GO term within individual sets of metal tolerance-modulating genes with their representation in the yeast genome. Interactions between metal tolerance-modulating genes were identified computationally using the Network Visualization System Osprey [103] and visualized as specified in the BioGRID database (version 2.035 release) [22] and in the Osprey reference manual. Subnetworks were defined as a minimum of three interacting gene products sharing at least one GO biologic process annotation and connected by at least two physical (two-hybrid, affinity capture-western, affinity capture-MS, or reconstituted complex) or genetic (synthetic lethality, synthetic growth defect, synthetic rescue, dosage rescue, phenotypic suppression, or phenotypic enhancement) interactions. $P$ values for individual subnetworks were determined by a onetailed test based on the hypergeometric distribution, using the lowest possible 'child term' (the one yielding the lowest $P$ value) allowed by the present GO categorization. Random samplings of $\mathrm{N}$ proteins (where $\mathrm{N}$ is the number of toxicitymodulating gene products in the three sets of metal sensitivity-conferring mutations [cadmium/nickel, nickel, and cadmium]) were performed 10,000 times using a script written in Perl and the above-mentioned criteria, leaving out essential genes. They respectively yielded averages of 1.2, 2.1 and 9.5 subnetworks, as compared with the 9,11 and 16 subnetworks identified with the cadmium/nickel (79 proteins), nickel (118 proteins), and cadmium (303 proteins) sets.

\section{Abbreviations}

ALP, alkaline phosphatase; ESCRT, endosomal sorting complexes required for transport; GO, Gene Ontology; GSH, reduced glutathione; HS, high sensitivity; LS, low sensitivity; MS, medium sensitivity; $\mathrm{OD}_{600}$, optical density at $600 \mathrm{~nm}$; ORF, open reading frame; PBS, phosphate-buffered saline; PVC, prevacuolar compartment; WT, wild-type; YPD, yeast extract-peptone-dextrose.

\section{Authors' contributions}

RR performed genome phenotyping screens, serial dilution, over-expression and Newport Green staining assays as well as data analysis. GM performed genome phenotyping screens and serial dilution assays. SO conceived the study and wrote the paper.

\section{Additional data files}

The following additional data are available with the online version of this paper. Additional data file 1 provides representative primary screen data and serial dilution growth assays. Additional data file 2 shows detailed phenotypes and related information on the genes whose disruption affects metal tolerance. Additional data file 3 shows interaction subnetworks for gene products whose disruption causes nickel specific sensitivity. Additional data file 4 shows interaction subnetworks involved in cadmium-specific sensitivity Additional data file 5 illustrates broad-range metal uptake system mutants that affect cadmium tolerance. Additional data file 6 shows enhanced nickel tolerance conferred by disruption of the Tna1 and Fur4 transporters. Additional data file 7 provides the multimetal screen database.

\section{Acknowledgements}

We thank our colleagues at the Department of Biochemistry and Molecular Biology, University of Parma, for help with statistical analysis (Riccardo Percudani), advice on metal chemistry (Angelo Merli), and for critical reading 
of the manuscript (Giorgio Dieci and Barbara Montanini). We are also grateful to Dan Burke (Department of Biochemistry and Molecular Genetics, University of Virginia) for advice on the use of the 384-multipinner replicator; to Roberto Tirindelli (Department of Neurosciences, University of Parma), and to Erasmo Neviani and Benedetta Bottari (Department of Genetics, University of Parma) for sharing their fluorescence microscopy instrumentation; and to Claudia Donnini (Department of Genetics, University of Parma) for the gift of the EUROSCARF control strains. This work was supported by the Regione Emilia-Romagna (PRRIITT Program SIQUAL), by the Ministry of University and Research (PRIN), and by a grant from the Fondazione Cariparma.

\section{References}

I. Valko M, Morris H, Cronin MT: Metals, toxicity and oxidative stress. Curr Med Chem 2005, I 2: | 16I-1 208.

2. International Agency for Research on Cancer (IARC): Chromium, Nickel and Welding: IARC Monographs on the Evaluation of Carcinogenic Risks to Humans 1990, 49: [http://monographs.iarc.fr/ENG/Mono graphs/vol49/volume49.pdf]. Lyon, France: IARC

3. International Agency for Research on Cancer (IARC): Beryllium, Cadmium, Mercury, and Exposures in the Glass Manufacturing Industry: IARC Monographs on the Evaluation of Carcinogenic Risks to Humans 1993, 58: [http://monographs.iarc.fr/ENG/Monographs/vol58/volume58.pdf]. Lyon, France: IARC

4. Beyersmann D: Effects of carcinogenic metals on gene expression. Toxicol Lett 2002, 1 27:63-68.

5. Costa M, Davidson TL, Chen H, Ke Q, Zhang P, Yan Y, Huang C, Kluz $\mathrm{T}$ : Nickel carcinogenesis: epigenetics and hypoxia signaling. Mutat Res 2005, 592:79-88.

6. Giaginis C, Gatzidou E, Theocharis S: DNA repair systems as targets of cadmium toxicity. Toxicol Appl Pharmacol 2006, 21 3:282-290.

7. Tamás MJ, Labarre J, Toledano MB, Wysocki R: Mechanisms of toxic metal tolerance in yeast. In Topics in Current Genetics (Molecular Biology of Metal Homeostasis and Detoxification) Volume 14. Edited by: Hohmann S. Heidelberg, Germany: Springer; 2006:395-454.

8. Jin YH, Clark AB, Slebos RJ, Al-Refai H, Taylor JA, Kunkel TA, Resnick MA, Gordenin DA: Cadmium is a mutagen that acts by inhibiting mismatch repair. Nat Genet 2003, 34:326-329.

9. Howlett NG, Avery SV: Induction of lipid peroxidation during heavy metal stress in Saccharomyces cerevisiae and influence of plasma membrane fatty acid unsaturation. Appl Environ Microbiol I 997, 63:297I-2976.

10. Li ZS, Lu YP, Zhen RG, Szczypka M, Thiele DJ, Rea PA: A new pathway for vacuolar cadmium sequestration in Saccharomyces cerevisiae: YCFI-catalyzed transport of bis(glutathionato)cadmium. Proc Natl Acad Sci USA 1997, 94:42-47.

II. Momose $\mathrm{Y}$, Iwahashi H: Bioassay of cadmium using a DNA microarray: genome-wide expression patterns of Saccharomyces cerevisiae response to cadmium. Environ Toxicol Chem 200I, 20:2353-2360.

12. Fauchon M, Lagniel G, Aude JC, Lombardia L, Soularue P, Petat C, Marguerie G, Sentenac A, Werner M, Labarre J: Sulfur sparing in the yeast proteome in response to sulfur demand. Mol Cell 2002, 9:713-723

13. Vido K, Spector D, Lagniel G, Lopez S, Toledano MB, Labarre J: A proteome analysis of the cadmium response in Saccharomyces cerevisiae. J Biol Chem 200I, 276:8469-8474.

14. Begley TJ, Rosenbach AS, Ideker T, Samson LD: Damage recovery pathways in Saccharomyces cerevisiae revealed by genomic phenotyping and interactome mapping. Mol Cancer Res 2002, I: $103-112$.

15. Birrell GW, Brown JA, Wu HI, Giaever G, Chu AM, Davis RW, Brown JM: Transcriptional response of Saccharomyces cerevisiae to DNA-damaging agents does not identify the genes that protect against these agents. Proc Natl Acad Sci USA 2002, 99:8778-8783

16. Klein CB, Conway K, Wang XW, Bhamra RK, Lin XH, Cohen MD, Annab L, Barrett JC, Costa M: Senescence of nickel-transformed cells by an $\mathbf{X}$ chromosome: possible epigenetic control. Science 1991, 251:796-799.

17. Lee YW, Klein CB, Kargacin B, Salnikow K, Kitahara J, Dowjat K, Zhitkovich A, Christie NT, Costa M: Carcinogenic nickel silences gene expression by chromatin condensation and DNA methylation: a new model for epigenetic carcinogens. Mol Cell Biol 1995, I 5:2547-2557.

18. Giaever G, Chu AM, Ni L, Connelly C, Riles L, Véronneau S, Dow S, Lucau-Danila A, Anderson K, André B, Arkin AP, Astromoff A, ElBakkoury M, Bangham R, Benito R, Brachat S, Campanaro S, Curtiss M, Davis K, Deutschbauer A, Entian KD, Flaherty P, Foury F, Garfinkel DJ, Gerstein M, Gotte D, Güldener U, Hegemann JH, Hempel S, Herman Z, et al.: Functional profiling of the Saccharomyces cerevisiae genome. Nature 2002, 4I 8:387-39l.

19. Winzeler EA, Shoemaker DD, Astromoff A, Liang $\mathrm{H}$, Anderson K, Andre B, Bangham R, Benito R, Boeke JD, Bussey H, Chu AM, Connelly C, Davis K, Dietrich F, Dow SW, El Bakkoury M, Foury F, Friend SH, Gentalen E, Giaever G, Hegemann JH, Jones T, Laub M, Liao H, Liebundguth N, Lockhart DJ, Lucau-Danila A, Lussier M, M'Rabet N, Menard P, et al:: Functional characterization of the $S$. cerevisiae genome by gene deletion and parallel analysis. Science 1999, 285:90I-906.

20. Hartwig A, Asmuss M, Ehleben I, Herzer U, Kostelac D, Pelzer A, Schwerdtle T, Burkle A: Interference by toxic metal ions with DNA repair processes and cell cycle control: molecular mechanisms. Environ Health Perspect 2002, I I 0(suppl 5):797-799.

21. Ke Q, Davidson T, Kluz T, Oller A, Costa M: Fluorescent tracking of nickel ions in human cultured cells. Toxicol Appl Pharmacol 2007, 21 9:18-23.

22. BioGRID Database [http://www.thebiogrid.org/]

23. Begley TJ, Rosenbach AS, Ideker T, Samson LD: Hot spots for modulating toxicity identified by genomic phenotyping and localization mapping. Mol Cell 2004, I6: I 17-125.

24. Tong AH, Lesage G, Bader GD, Ding H, Xu H, Xin X, Young J, Berriz GF, Brost RL, Chang M, Chen Y, Cheng X, Chua G, Friesen H, Goldberg DS, Haynes J, Humphries C, He G, Hussein S, Ke L, Krogan N, Li Z, Levinson JN, Lu H, Ménard P, Munyana C, Parsons AB, Ryan O, Tonikian R, Roberts T, et al.: Global mapping of the yeast genetic interaction network. Science 2004, 303:808-8।3.

25. Kane PM: The where, when, and how of organelle acidification by the yeast vacuolar $\mathbf{H}^{+}$-ATPase. Microbiol Mol Biol Rev 2006, 70:177-19|.

26. Oluwatosin YE, Kane PM: Mutations in the CYS4 gene provide evidence for regulation of the yeast vacuolar H+-ATPase by oxidation and reduction in vivo. I Biol Chem 1997, 272:28I49-28I57.

27. Raymond CK, Howald-Stevenson I, Vater CA, Stevens TH: Morphological classification of the yeast vacuolar protein sorting mutants: evidence for a prevacuolar compartment in class $E$ vps mutants. Mol Biol Cell 1992, 3:1389-1402.

28. Rothman JH, Howald I, Stevens TH: Characterization of genes required for protein sorting and vacuolar function in the yeast Saccharomyces cerevisiae. EMBO J 1989, 8:2057-2065.

29. Rudge SA, Anderson DM, Emr SD: Vacuole size control: regulation of Ptdlns $(3,5) P 2$ levels by the vacuole-associated Vacl 4Fig4 complex, a Ptdins(3,5)P2-specific phosphatase. Mol Biol Cell 2004, 15:24-36.

30. Yamamoto A, DeWald DB, Boronenkov IV, Anderson RA, Emr SD, Koshland D: Novel PI(4)P 5-kinase homologue, Fab Ip, essential for normal vacuole function and morphology in yeast. Mol Biol Cell 1995, 6:525-539.

31. Forzani C, Lobreaux S, Mari S, Briat JF, Lebrun M: Metal resistance in yeast mediated by the expression of a maize $20 S$ proteasome alpha subunit. Gene 2002, 293:199-204.

32. Haugen AC, Kelley R, Collins JB, Tucker CJ, Deng C, Afshari CA, Brown JM, Ideker T, Van Houten B: Integrating phenotypic and expression profiles to map arsenic-response networks. Genome Biol 2004, 5:R95.

33. Jungmann J, Reins HA, Schobert C, Jentsch S: Resistance to cadmium mediated by ubiquitin-dependent proteolysis. Nature 1993, 36 I:369-371.

34. Dudley AM, Janse DM, Tanay A, Shamir R, Church GM: A global view of pleiotropy and phenotypically derived gene function in yeast. Mol Syst Biol 2005, I:2005 000 I.

35. Gustin MC, Albertyn J, Alexander M, Davenport K: MAP kinase pathways in the yeast Saccharomyces cerevisiae. Microbiol Mol Biol Rev 1998, 62: 1264-1300.

36. Jonak C, Nakagami H, Hirt H: Heavy metal stress. Activation of distinct mitogen-activated protein kinase pathways by copper and cadmium. Plant Physiol 2004, 136:3276-3283.

37. Tucker M, Staples RR, Valencia-Sanchez MA, Muhlrad D, Parker R: Ccr4p is the catalytic subunit of a Ccr4p/Pop2p/Notp mRNA deadenylase complex in Saccharomyces cerevisiae. EMBO J 
2002, 2 | : |427-|436

38. Traven A, Hammet A, Tenis N, Denis CL, Heierhorst J: Ccr4-not complex mRNA deadenylase activity contributes to DNA damage responses in Saccharomyces cerevisiae. Genetics 2005, 169:65-75.

39. Jo WJ, Loguinov A, Chang M, Wintz H, Nislow C, Arkin AP, Giaever $G$, Vulpe $C D$ : Identification of genes involved in the toxic response of Saccharomyces cerevisiae against iron and copper overload by parallel analysis of deletion mutants. Toxicol Sci 2008, I01:|40-151.

40. Bilsland E, Molin C, Swaminathan S, Ramne A, Sunnerhagen P: Rck I and Rck2 MAPKAP kinases and the HOG pathway are required for oxidative stress resistance. Mol Microbiol 2004, 53:1743-1756.

4I. Aouida M, Page N, Leduc A, Peter M, Ramotar D: A genome-wide screen in Saccharomyces cerevisiae reveals altered transport as a mechanism of resistance to the anticancer drug bleomycin. Cancer Res 2004, 64: I I02-II09.

42. Bennett CB, Lewis LK, Karthikeyan G, Lobachev KS, Jin YH, Sterling JF, Snipe JR, Resnick MA: Genes required for ionizing radiation resistance in yeast. Nat Genet 200I, 29:426-434.

43. Chang $M$, Bellaoui $M$, Boone $C$, Brown GW: A genome-wide screen for methyl methanesulfonate-sensitive mutants reveals genes required for $\mathbf{S}$ phase progression in the presence of DNA damage. Proc Natl Acad Sci USA 2002, 99:16934-16939.

44. Serrano R, Bernal D, Simon E, Arino J: Copper and iron are the limiting factors for growth of the yeast Saccharomyces cerevisiae in an alkaline environment. I Biol Chem 2004, 279:19698-19704.

45. Thorpe GW, Fong CS, Alic N, Higgins VJ, Dawes IW: Cells have distinct mechanisms to maintain protection against different reactive oxygen species: oxidative-stress-response genes. Proc Natl Acad Sci USA 2004, 10 1:6564-6569.

46. Askwith CC, de Silva D, Kaplan J: Molecular biology of iron acquisition in Saccharomyces cerevisiae. Mol Microbiol 1996, 20:27-34.

47. Pagani MA, Casamayor A, Serrano R, Atrian S, Arino J: Disruption of iron homeostasis in Saccharomyces cerevisiae by high zinc levels: a genome-wide study. Mol Microbiol 2007, 65:52 I-537.

48. Davidson T, Chen H, Garrick MD, D'Angelo G, Costa M: Soluble nickel interferes with cellular iron homeostasis. Mol Cell Biochem 2005, 279: I57-162.

49. Raja KB, Jafri SE, Peters TJ, Simpson RJ: Iron and cadmium uptake by duodenum of hypotransferrinaemic mice. Biometals 2006 1 9:547-553.

50. Wang HY, Klatte M, Jakoby M, Baumlein H, Weisshaar B, Bauer P: Iron deficiency-mediated stress regulation of four subgroup Ib $\mathrm{BHLH}$ genes in Arabidopsis thaliana. Planta 2007, 226:897-908.

5I. Yoshihara T, Hodoshima H, Miyano Y, Shoji K, Shimada H, Goto F: Cadmium inducible $F e$ deficiency responses observed from macro and molecular views in tobacco plants. Plant Cell Rep 2006, 25:365-373.

52. Liu XF, Supek F, Nelson N, Culotta VC: Negative control of heavy metal uptake by the Saccharomyces cerevisiae BSD2 gene. J Biol Chem 1997, 272: I 1763-1 I769.

53. Dix D, Bridgham J, Broderius M, Eide D: Characterization of the FET4 protein of yeast. Evidence for a direct role in the transport of iron. J Biol Chem 1997, 272: I I770-I I 777.

54. Liu XF, Culotta VC: Post-translation control of Nramp metal transport in yeast. Role of metal ions and the BSD2 gene. J Biol Chem 1999, 274:4863-4868.

55. Dix DR, Bridgham JT, Broderius MA, Byersdorfer CA, Eide DJ: The FET4 gene encodes the low affinity $\mathrm{Fe}(\mathrm{II})$ transport protein of Saccharomyces cerevisiae. J Biol Chem 1994, 269:26092-26099.

56. Cohen A, Nelson H, Nelson N: The family of SMF metal ion transporters in yeast cells. I Biol Chem 2000, 275:33388-33394.

57. Waters BM, Eide DJ: Combinatorial control of yeast FET4 gene expression by iron, zinc, and oxygen. J Biol Chem 2002, 277:33749-33757.

58. Schumann K, Friebel P, Schmolke G, Elsenhans B: State of iron repletion and cadmium tissue accumulation as a function of growth in young rats after oral cadmium exposure. Arch Environ Contam Toxicol 1996, 3 I :483-487.

59. Chen H, Davidson T, Singleton S, Garrick MD, Costa M: Nickel decreases cellular iron level and converts cytosolic aconitase to iron-regulatory protein I in A549 cells. Toxicol Appl Pharmacol 2005, 206:275-287.
60. Lutsenko S, Barnes NL, Bartee MY, Dmitriev OY: Function and regulation of human copper-transporting ATPases. Physiol Rev 2007, 87: 101 I-1046.

6I. Mims MP, Prchal JT: Divalent metal transporter I. Hematology 2005, 10:339-345.

62. Li W, Mitchell AP: Proteolytic activation of Rim Ip, a positive regulator of yeast sporulation and invasive growth. Genetics 1997, | 45:63-73.

63. Lamb TM, Xu W, Diamond A, Mitchell AP: Alkaline response genes of Saccharomyces cerevisiae and their relationship to the RIMIOI pathway. J Biol Chem 200I, 276: I850- I856.

64. Lamb TM, Mitchell AP: The transcription factor Rim I O I p governs ion tolerance and cell differentiation by direct repression of the regulatory genes NRGI and SMPI in Saccharomyces cerevisiae. Mol Cell Biol 2003, 23:677-686.

65. Castrejon F, Gomez A, Sanz M, Duran A, Roncero C: The RIMIOI pathway contributes to yeast cell wall assembly and its function becomes essential in the absence of mitogen-activated protein kinase SIt2p. Eukaryot Cell 2006, 5:507-5I7.

66. Vyas VK, Berkey CD, Miyao T, Carlson M: Repressors Nrg I and Nrg2 regulate a set of stress-responsive genes in Saccharomyces cerevisiae. Eukaryot Cell 2005, 4:I882-I89I.

67. Closs El, Boissel JP, Habermeier A, Rotmann A: Structure and function of cationic amino acid transporters (CATs). J Membr Biol 2006, 2 I 3:67-77.

68. MacDiarmid CW, Gaither LA, Eide D: Zinc transporters that regulate vacuolar zinc storage in Saccharomyces cerevisiae. EMBO J 2000, I 9:2845-2855.

69. Nelson N, Perzov N, Cohen A, Hagai K, Padler V, Nelson H: The cellular biology of proton-motive force generation by $\mathrm{V}$ ATPases. J Exp Biol 2000, 203:89-95.

70. Stimpson HE, Lewis MJ, Pelham HR: Transferrin receptor-like proteins control the degradation of a yeast metal transporter. EMBO / 2006, 25:662-672.

7I. Swaminathan S, Amerik AY, Hochstrasser M: The Doa4 deubiquitinating enzyme is required for ubiquitin homeostasis in yeast. Mol Biol Cell 1999, 10:2583-2594.

72. Wolfe D, Reiner T, Keeley JL, Pizzini M, Keil RL: Ubiquitin metabolism affects cellular response to volatile anesthetics in yeast. Mol Cell Biol 1999, 19:8254-8262.

73. Bishop AL, Rab FA, Sumner ER, Avery SV: Phenotypic heterogeneity can enhance rare-cell survival in 'stress-sensitive' yeast populations. Mol Microbiol 2007, 63:507-520.

74. Borrelly G, Boyer JC, Touraine B, Szponarski W, Rambier M, Gibrat $\mathrm{R}$ : The yeast mutant vps5-delta affected in the recycling of Golgi membrane proteins displays an enhanced vacuolar $\mathrm{Mg}^{+} / \mathrm{H}^{+}$exchange activity. Proc Natl Acad Sci USA 200I, 98:9660-9665.

75. Bowers K, Lottridge J, Helliwell SB, Goldthwaite LM, Luzio JP, Stevens $\mathrm{TH}$ : Protein-protein interactions of ESCRT complexes in the yeast Saccharomyces cerevisiae. Traffic 2004, 5: 194-210.

76. Hurley JH, Emr SD: The ESCRT complexes: structure and mechanism of a membrane-trafficking network. Annu Rev Biophys Biomol Struct 2006, 35:277-298.

77. Seaman MN: Recycle your receptors with retromer. Trends Cell Biol 2005, 15:68-75.

78. Strochlic TI, Setty TG, Sitaram A, Burd CG: GrdI9/Snx3p functions as a cargo-specific adapter for retromer-dependent endocytic recycling. J Cell Biol 2007, I 77: I I5- I 25.

79. Shaw JD, Cummings KB, Huyer G, Michaelis S, Wendland B: Yeast as a model system for studying endocytosis. Exp Cell Res 200I, 27I:I-9.

80. Hettema EH, Lewis MJ, Black MW, Pelham HR: Retromer and the sorting nexins Snx4/41/42 mediate distinct retrieval pathways from yeast endosomes. EMBO J 2003, 22:548-557.

8I. Seaman MN: Cargo-selective endosomal sorting for retrieval to the Golgi requires retromer. J Cell Biol 2004, I 65: I I I- I 22.

82. Portnoy ME, Liu XF, Culotta VC: Saccharomyces cerevisiae expresses three functionally distinct homologues of the nramp family of metal transporters. Mol Cell Biol 2000, 20:7893-7902.

83. Nishimura K, Igarashi K, Kakinuma $\mathrm{Y}$ : Proton gradient-driven nickel uptake by vacuolar membrane vesicles of Saccharomyces cerevisiae. J Bacteriol 1998, I80:1962-1964.

84. Eide DJ, Clark S, Nair TM, Gehl M, Gribskov M, Guerinot ML, Harper JF: Characterization of the yeast ionome: a genome-wide analysis of nutrient mineral and trace element homeostasis in Saccharomyces cerevisiae. Genome Biol 2005, 6:R77. 
85. Stark C, Breitkreutz BJ, Reguly T, Boucher L, Breitkreutz A, Tyers M: BioGRID: a general repository for interaction datasets. Nucleic Acids Res 2006, 34:D535-539.

86. Care A, Vousden KA, Binley KM, Radcliffe P, Trevethick J, Mannazzu I, Sudbery PE: A synthetic lethal screen identifies a role for the cortical actin patch/endocytosis complex in the response to nutrient deprivation in Saccharomyces cerevisiae. Genetics 2004, 1 66:707-719.

87. Burda P, Padilla SM, Sarkar S, Emr SD: Retromer function in endosome-to-Golgi retrograde transport is regulated by the yeast Vps34 Ptdlns 3-kinase. J Cell Sci 2002, I I 5:3889-3900.

88. Luo W, Chang A: An endosome-to-plasma membrane pathway involved in trafficking of a mutant plasma membrane ATPase in yeast. Mol Biol Cell 2000, I I:579-592.

89. Nothwehr SF, Ha SA, Bruinsma P: Sorting of yeast membrane proteins into an endosome-to-Golgi pathway involves direct interaction of their cytosolic domains with Vps35p. J Cell Biol 2000, I 5 I:297-3 I0.

90. Yang M, Jensen LT, Gardner AJ, Culotta VC: Manganese toxicity and Saccharomyces cerevisiae Mam3p, a member of the ACDP (ancient conserved domain protein) family. Biochem J 2005, 386:479-487.

91. Zahler WL, Cleland WW: A specific and sensitive assay for disulfides. J Biol Chem 1968, 243:716-719.

92. Horton JD, Cohen JC, Hobbs HH: Molecular biology of PCSK9: its role in LDL metabolism. Trends Biochem Sci 2007, 32:7I-77.

93. Fields M, Lewis CG: Hepatic iron overload may contribute to hypertriglyceridemia and hypercholesterolemia in copperdeficient rats. Metabolism 1997, 46:377-38I.

94. Yeh TY, Sbodio JI, Nguyen MT, Meyer TN, Lee RM, Chi NW: Tankyrase-I overexpression reduces genotoxin-induced cell death by inhibiting PARPI. Mol Cell Biochem 2005, 276: I83-192.

95. Puig S, Askeland E, Thiele DJ: Coordinated remodeling of cellular metabolism during iron deficiency through targeted mRNA degradation. Cell 2005, I20:99-I I0.

96. Holland S, Lodwig E, Sideri T, Reader T, Clarke I, Gkargkas K, Hoyle DC, Delneri D, Oliver SG, Avery SV: Application of the comprehensive set of heterozygous yeast deletion mutants to elucidate the molecular basis of cellular chromium toxicity. Genome Biol 2007, 8:R268.

97. Yeast Deletion Mutant Database [http://www-sequence.stan ford.edu/group/yeast_deletion_project/deletions3.html]

98. Persans MW, Nieman K, Salt DE: Functional activity and role of cation-efflux family members in $\mathrm{Ni}$ hyperaccumulation in Thlaspi goesingense. Proc Natl Acad Sci USA 200 I, 98:9995-10000.

99. Saccharomyces Genome Database (SGD) [http://www.yeastge nome.org/]

100. Ito H, Fukuda $Y$, Murata $K$, Kimura A: Transformation of intact yeast cells treated with alkali cations. I Bacteriol 1983, 153:163-168.

I0I. Princeton Protein Orthology Database (P-POD) [http:// ortholog.princeton.edu/help.html]

102. Online Mendelian Inheritance in Man (OMIM) [http:// www.ncbi.nlm.nih.gov/sites/entrez?db=omim]

103. Network Visualization System Osprey [http://bio
a data.mshri.on.ca/osprey]

104. EPCLUST [http://www.bioinf.ebc.ee/EP/EP/EPCLUST/] 